\title{
A Cognitive-Ecological Approach to Temporal Self-Appraisal
}

\author{
Matthew Baldwin \\ University of Florida
}

\author{
Hans Alves \\ University of Cologne
}

\author{
Christian Unkelbach \\ University of Cologne
}

\begin{abstract}
According to the evaluative information ecology model of social-comparison, people are more similar on their positive traits and tend to differ on their negative traits. This means that comparisons based on differences will naturally produce negative evaluations, whereas those based on similarities will produce positive evaluations. In this research we apply and extend this model to theorize about the outcomes of temporal self-comparisons. We predicted that one's similarities across time would be evaluated positively, whereas one's differences would be evaluated more negatively. However, because positive attributes are reinforced over time, we expected an asymmetry to emerge such that attributes unique to the past self (past differences) would be most negative. Evidence from a simulation study, 7 experiments (total $N=1844$ ), and an integrative data analysis, support the notion that temporal self-appraisals follow naturally from comparisons in a known information ecology. Several tests of the prevailing motivatedself-perception account did not bear fruit. We discuss the implications of these findings for temporal self-appraisal theory as well as other aspects of self and identity.
\end{abstract}

Keywords: temporal self-appraisal, temporal comparison, information ecology, self and identity, self-enhancement

We all have our time machines, don't we? Those that take us back are memories, and those that carry us forward are dreams.

— Über-Morlock, The Time Machine

\section{Introduction}

From philosophy to folk beliefs, the subjective progress of time is essential to the concept of the self. In fact, Heidegger (1962) contended that existence and time are one in the same-we are thrown into a stream of possibility, stretched between birth and death by our awareness of having been before in the past, and ability to project ourselves into the future. Accepting their place in time is a life-long project for people (Bluck and Levine, 1998; Habermas and Bluck, 2000), and mentally traveling back and forth between memories of the past and dreams of the future is fundamental to how people construct an identity that has purpose, significance, and coherence (McAdams, 2008; McAdams and McLean, 2013; McAdams and Pals, 2006). Here, we examine some basic principles that underlie the nature of this tem-

Matthew Baldwin (10) https://orcid.org/0000-0002-7355-478X

Address Correspondence to: Matthew Baldwin, $524 \mathrm{Mc}-$ Carty Hall C, Department of Psychology, University of Florida, Gainesville, FL, 32603, mbaldwin1@ufl.edu, 352-328-2494 poral self. Specifically, we lean on insights gained from a recent cognitive-ecological approach to evaluative information processing (Alves et al., 2017a, 2017b, 2018, 2019; Fiedler, 2000) to examine the nature and consequences of comparing the self across time. Specifically, we examine how the evaluative information ecology (Unkelbach et al., 2019) shapes self-evaluations that result from temporal comparisons.

\section{Temporal Comparison}

Comparison is a building block of human social life (Festinger, 1954), having an influence in domains as diverse as stereotyping (Biernat, 2003), person perception (Herr, 1986; Higgins and Lurie, 1983), attitudes (Sherif and Hovland, 1961), and affect (Epstude and Mussweiler, 2009). Broadly speaking, whenever information is perceived, processed, or evaluated, it is almost inevitably compared to an available standard Kahneman and Miller, 1986). And although other mammals engage in comparative thinking, and can exhibit rudimentary displays of social comparison (Dumas et al., 2017; Keupp et al., 2019; Schmitt et al., 2016; J. Suls et al., 2019), humans are probably unique in their ability to compare themselves across time (Suddendorf and Busby, 2003). People have the unique ability to comparatively consider who they were, who they are, and who they might become (McAdams and McLean, 2013; Ricoeur, 1991). This means that deciding who one is today depends not only on comparisons to relevant others (Festinger, 1954) but also to who one 
was yesterday (Albert, 1977) or will be tomorrow (Markus and Nurius, 1987; Ryff, 1991). Thus, the function of temporal self-comparison, much like social comparisons with others, is to gain information about the self that is relevant for judgements of one's abilities, attributes, character, and trajectory in life.

One systematic attempt to describe the rules that govern this functional goal (i.e., gathering of relevant information about the self over time) was done by Albert (Albert, 1977), who translated Festinger's (1954) seminal work on social comparison into a theory of temporal comparison with a primary focus on the nature and consequences of comparing the present self to the past self. In the sections that follow, we summarize some key points of Albert's theory and review some of the more recent research that was inspired by his work.

\section{Self-Continuity Motive}

Borrowing from Festinger's language, Albert hypothesized that people have a drive to compare the present self to the past self in service of maintaining an enduring, coherent, and integrated identity over time. It was thought that people would strategically choose to compare with past-selves that are consistent with their current-selves; that is, to focus on similarities between the present and the (recent) past. Albert hypothesized that the drive for these kinds of comparisons would be particularly strong during times of change, when one's sense of an enduring self-concept would be under threat (Albert, 1977).

These ideas are generally supported by research showing that people rely on their autobiographies as a guide for integrating unexpected events into a coherent story; and as a way to interpret change, especially in service of maintaining continuity (Bluck et al., 2005). When certain events are experienced as separating a desired future from the present, people appear to be motivated to close this gap in time by pursuing goals that bring the present in line with the future self (Peetz and Wilson, 2013). Other research shows that specific types of past-comparisons are utilized when faced with feelings of discontinuity. For instance, people report feeling more nostalgic when self-continuity is threatened, and recalling nostalgic memories can promote self-continuity in the face of those threats (Sedikides et al., 2016).

However, other observations somewhat contradict the notion that people are driven by a general need for continuity, and that temporal comparisons work to satisfy this need. For instance, when comparing to past and future-selves, people tend to treat those selves as 'others' and exhibit typical actor-observer effects when evaluating those selves (Pronin and Ross, 2006). If people are motivated to see the self as one coherent whole, one must wonder why past-selves and future-selves are experienced as 'others.' Also, people do expect to change over time, and in particular, expect to change for the better (O'brien and Kardas, 2016). In fact, explicit self-discontinuity sometimes promotes positive outcomes, as research on the fresh start effect attests (Dai and $\mathrm{Li}, 2019$ ). When a temporal landmark signifies the beginning of a new time period, people tend to be more motivated to initiate goal pursuit, in part because they feel disassociated from the past. People have also been shown to use temporal landmarks strategically_creating temporal discontinuity between the present and the future in order to maintain a positive self-view (Peetz and Wilson, 2014). These findings suggest that comparing across time can also serve the function of self-enhancement, even at the cost of self-continuity (i.e., when considering differences in the self across time).

\section{Self-Enhancement Motive}

Although Albert was mostly silent on the idea that temporal comparison can serve the purpose of self-enhancement, research inspired by his work has focused on this function. Most people are inclined to feel good about themselves (Baumeister, 1999; Leary, 1999; Sedikides et al., 2003). This tendency is often described as a motivational force-people strive to hold themselves in high regard, so much so that they often 'deceive' themselves into believing that they are good even when objective evidence is lacking or contradictory (Ditto and Boardman, 1995; Doosje et al., 1995; McAdams, 2008; Ryff, 1991; Tesser, 1988). These positive illusions come from a myriad of sources identified in prior research; from exaggerating perceptions of control (Langer, 1975), to attributing success to oneself and failure to external influences (Mezulis et al., 2004), to engaging in strategic comparisons with others (Corcoran et al., 2011; J. M. Suls and Miller, 1977). The temporally extended nature of the self poses an interesting problem for the self-enhancement motive, because the question facing individuals might be which self to enhance at what point in time. One way to deal with this problem might be to simply decide that one has always been good, and only focus on those similarities over time; this would boost and maintain self-regard and satisfy the need for self-stability and continuity. However, when considering the temporal nature of the self, people also tend to expect self-improvement (O'brien and Kardas, 2016). As the research presented earlier reveals, people sometimes feel that they are not, or have not always been good, and will strategically separate, or contrast away from negative temporal selves in service of self-enhancement (Peetz and Wilson, 2013, 2014).

Thus, rather than self-enhance by focusing on stable positive qualities of the self over time, it appears as though people look for ways they have changed (or will change) for the better. This particular self-evaluation has now been covered extensively by temporal self-appraisal theory (M. Ross and Wilson, 2000, 2003; Wilson and Ross, 2000, 2001), which proposes that people self-enhance by disparaging distant past-selves who have little bearing on the present self. Couched squarely in the self-enhancement tradition, the the- 
ory argues that this process is motivated and, in some ways, deceptive. Even when no actual improvement has occurred, people seem to distance from past-selves, disparage them, and trick themselves into believing that they have changed for the better (Wilson and Ross, 2001). In sum, temporal self-appraisal theory states that: (1) people are motivated to feel good about themselves in the present and (2) they can achieve this goal by comparing to the past self that is perceived as distant and negative. Thus, the perception of improvement is motivated and people can even lead themselves into believing that it has occurred when it has not.

\section{Toward an Alternative Account}

Although there is strong evidence for this motivated selfperception, we suggest that temporal self-appraisal theory (M. Ross and Wilson, 2000, 2003) is incomplete. For one, temporal self-appraisal theory does not explain why past self disparagement is the default. Research suggests that when people think about self-change, they understand that to mean change for the better (O'brien and Kardas, 2016). Under this principle, self-enhancement could also manifest as present self praise rather than past self disparagement. One could just as easily evaluate the past self as good and also evaluate the present self as having improved beyond it. Alternatively, one could avoid thinking about change altogether and instead focus on the continuity of the self. Considering that people already hold positive views of themselves, projecting those positive features back and forth in time should further reinforce positive self-regard. This occurs, for instance, when people reflect nostalgically on the past and subsequently report greater self-esteem. Because nostalgic selves are perceived as more 'true' of oneself (Baldwin et al., 2015) and because nostalgia fosters self-continuity (Sedikides et al., 2016), the positive recollection of nostalgic selves should carry forward into the present and serve as a basis for selfenhancement. In the case of nostalgia, past-selves are seen through rose colored glasses, rather than disparaged, as temporal self-appraisal theory suggests. In fact, if people were to focus only on positive similarities, the need for continuity and self-regard would be satisfied. Why must one vilify the past when praising the present would serve the same selfenhancement function? Why must one evaluate differences at all, when a focus on stable positive attributes would serve the same function? We propose that the answers to these questions are best addressed by a cognitive-ecological model of comparison.

\section{The Evaluative Information Ecology}

In the current research, we built on recent insights summarized in the Evaluative Information Ecology (EvIE) model (Unkelbach et al., 2019; see also Unkelbach et al., 2020), which describes how the information ecology is structured with regard to its evaluative properties. This model suggests two general properties that underlie positive and negative in- formation in the world and that serve as the basis for evaluation. First, positive information such as words, traits, behaviors, events, or objects occurs more frequently than negative information. For example, positive words are used more frequently in written and spoken language, people usually expect others to behave positively, and the positivity of personality traits strongly correlates with their prevalence (Alves et al., 2017b; Wood and Furr, 2016). In short, the world around us is mostly positive, most of the time. Second, although positive information is more frequent, negative information is more diverse (Alves et al., 2017a). There are more ways to be negative than to be positive and this greater diversity of negativity is visible at various levels of observation and across many stimulus domains. For example, there are more unique words to describe negative things or negative people, and these negative words are less similar to one another. The same can be said for other stimuli such as faces, affective images, life events, and emotional reactions (Unkelbach et al., 2019). The reasons for liking something (e.g., ice cream), or somebody (e,g., a famous actor) are also highly similar, while there are many reasons to dislike something or somebody (Gershoff et al., 2007; Leising et al., 2013).

These properties have a crucial probabilistic influence on comparison processes. Most notably, the ecological distributions create a world where positive attributes are usually shared among attitude objects, whereas negative attributes are usually not shared among them. The converse is also true: shared attributes are usually positive, whereas distinct attributes are usually negative (Alves et al., 2017b, 2018). In other words, those attributes that differentiate people, groups, or objects are usually negative and those that connect them are usually positive. The implication is that any comparison process that highlights distinct, rather than shared attributes tends to highlight the negatives, which may result in 'biased' attitudes. For example, the fact that novel groups are typically judged based on attributes that differentiate them from familiar groups can explain why people often hold negative attitudes towards out-groups and minorities (Alves et al., 2018). The same holds for comparing people: when two people are compared on the basis of what they share, positive attributes will come to mind, but when compared on the basis of what they do not share, negative attributes will come to mind (Alves et al., 2017a, 2017b, 2018, 2019; Unkelbach et al., 2019).

The program of research just summarized is focused primarily on social comparison between different individuals or groups. In the current research, we aim to apply this ecological perspective to temporal comparisons of the self and pave the way for new predictions regarding the evaluation of the self across time. 
Table 1

Principles of the Temporal Evaluative Information Ecology

\begin{tabular}{|c|c|c|c|}
\hline Property of Information & Description & Social Comparison & Temporal Comparison \\
\hline Frequency & $\begin{array}{l}\text { Positive attributes are more } \\
\text { prevalent than negative at- } \\
\text { tributes }\end{array}$ & $\begin{array}{l}\text { Most of the time, two in- } \\
\text { dividuals' similarities are } \\
\text { more positive than their dif- } \\
\text { ferences }\end{array}$ & $\begin{array}{l}\text { Most of the time, an individ- } \\
\text { ual's similarities across two } \\
\text { points in time are more pos- } \\
\text { itive than their differences }\end{array}$ \\
\hline Diversity & $\begin{array}{l}\text { Positive attributes are more } \\
\text { alike than negative attributes }\end{array}$ & $\begin{array}{l}\text { Most of the time, two in- } \\
\text { dividuals' similarities are } \\
\text { more positive than their dif- } \\
\text { ferences }\end{array}$ & $\begin{array}{l}\text { Most of the time, an individ- } \\
\text { ual's similarities across two } \\
\text { points in time are more pos- } \\
\text { itive than their differences }\end{array}$ \\
\hline Growth & $\begin{array}{l}\text { Positive attributes are rein- } \\
\text { forced more than negative } \\
\text { attributes }\end{array}$ & & $\begin{array}{l}\text { Most of the time, individu- } \\
\text { als will improve across two } \\
\text { points in time }\end{array}$ \\
\hline
\end{tabular}

\section{The Information Ecology Across Time}

We now apply the EvIE assumptions to temporal comparisons, and delineate the implications of these assumptions for the outcomes of temporal comparisons. Crucially, we extend the model by a temporal factor; beyond frequency and diversity, we add a growth component over time. Table 1 summarizes the three principles of the evaluative information ecology and how they might extend to the temporal domain. Crucially, the growth principle states that positive attributes of an individual will be reinforced over time, whereas negative attributes will not. This leads to an interesting paradoxaccording to the diversity and frequency principles, focusing on the way that someone has changed over time will bring to mind negative attributes, as differences are typically negative. But according to the growth principle, focusing on the way that someone changes over time will bring to mind positive attributes, as positive attributes are reinforced over time. Testing the full range of possible self-comparisons over time is necessary to determine under what circumstances those comparisons result in positive or negative evaluations. We elaborate more on this next, starting with a more thorough translation of the EvIE model to temporal comparison.

Again, in general, positive information is more prevalent and less diverse than negative information (frequency and diversity principles). This implies that when two people are compared, their shared attributes will be positive and those that differentiate them will be negative. In terms of the temporal self, this implies that at any two points in time, attributes that have remained the same over time are likely to be positive, and the things that have changed are likely to be negative.

Notice that applying these first two principles would adequately explain the chump-to-champ effect whereby people tend to disparage their past selves (Wilson and Ross, 2001, 2003). People typically evaluate targets on basis of their differences to existing standards, because learning, categorization, and comparison, rely primarily on differentiating people, groups, and objects on the basis of their unique attributes (Alves, 2018; Alves et al., 2020). For example, when people form associations between categories and their attributes, more attention and weight is given to attributes that heighten between-category differences rather than betweencategory similarities (Krueger and Clement, 1994; Krueger et al., 1989). Unique attributes tend to define a category (Tversky and Gati, 1978). Assuming these processes apply to temporal comparisons as well, it can be assumed that people evaluate the past self on the basis of how it was different from the present self. This assumption is supported by the actor-observer effects found when people perceive their past-selves as 'others' (Pronin and Ross, 2006), and the fact that people expect the self to change (i.e., become differentiated) over time (O'brien and Kardas, 2016). Thus, a focus on differences combined with the properties of the information ecology can produce a perception that the past self was more negative. A motivated self-perception is not required to produce this result.

However, the diversity and frequency principles would also lead to a counter-intuitive outcome, namely, that present self differences would also be negative. If people focus on differences to evaluate the present self relative to the past, the ecological model predicts that the present self would be evaluated less positively. Thus, there are now competing predictions between an cognitive-ecological and a motivational account, as the latter would expect people to be motivated to avoid disparaging the present, or even motivated to exaggerate positive aspects of the present self when considering differences, as exaggerating positive differences would 

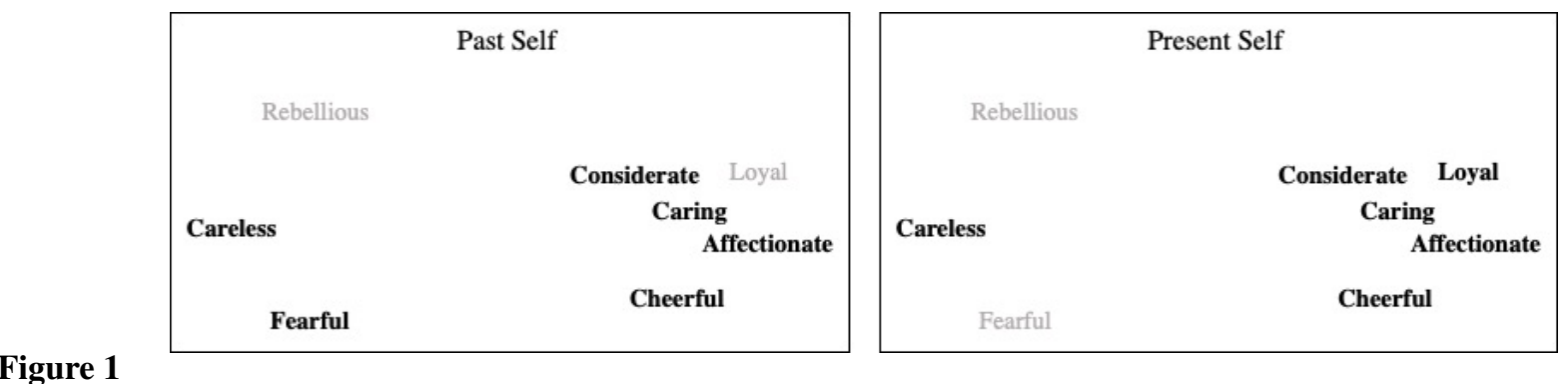

\section{Figure 1}

The growth principle in the temporal evaluative information ecology. Darker attributes are those that are possessed, and lighter attributes are those that are not possessed. The past self is more positive than negative with a 2:1 ratio of positive-tonegative attributes (frequency principle) and positive attributes are more similar to one another (diversity principle). Through reinforcement, the present self retains positive attributes but also gains a new one. No new negative attributes are gained and one negative attribute is lost. As a result, the present self is more positive with a ratio of 5:1 positive-to-negative attributes and has improved (growth principle).

be a suitable strategy for perceiving and exaggerating selfimprovement. Whether or not people engage in this strategy is yet unknown, however, because temporal self-appraisal research typically asks participants for general evaluations of past and present-selves (as opposed to relative evaluations of similarities and differences between the past and present). To fully understand what is driving temporal self-comparison effects, a new approach is needed that incorporates theory about how people change over time.

We propose that some attributes are reinforced over time, while others are not (henceforth, the growth principle, Table 1), and that most of the time it is positive attributes that are reinforced. From a young age, children are taught what is good and what is bad; positive behaviors and attributes grow stronger through reward and praise, whereas negative behaviors and attributes are weakened through punishment and lack of reinforcement. This means that people likely gain and maintain positive attributes at a greater rate over time compared to negative attributes, which are quickly lost and avoided. It feels good to be good, to learn, and to improve and it feels bad to fail and decline (Langston, 1994; Reis et al., 2010; Thorndike, 1898; see Unkelbach et al., 2019). The hedonic aspect of temporal self comparisons is built into the growth principle. People need no motivation to perceive self-improvement because, most of the time, people actually improve through reinforcement and learning.

Theoretically, attributes themselves could also reinforce each other to different degrees. Consider the attributes of a person as if they are arranged in a network, with some attributes being highly connected (i.e., similar), and others being highly disconnected (i.e., dissimilar; see Dalege et al., 2017; Dalege et al., 2018, 2019). In such a network, similar and connected attributes would reinforce one another, whereas dissimilar and disconnected attributes would not. For instance, being considerate might also reinforce being caring because the respective behaviors are similar and tend to co-occur. In contrast, two dissimilar attributes, such as careless and fearful, would not reinforce each other to the same degree, as the two tend not to co-occur. When considered in a network, the similarity between attributes is directly related to how 'activated' those attributes are. And this will apply not only to the way those attributes manifest in behavior (e.g., acting considerate also makes one caring) but also how salient they are in cognition (e.g., thinking about how one is considerate also brings to mind how one is caring). Over time this positive attribute network grows not only in strength but also size, because activating positive attributes that one possesses now (either through behavior or in cognition) is likely to activate closely related positive attributes that one does not yet possess. Although this idea is speculative and theoretical, similar principles have been shown to operate at the level of attitudes (Dalege et al., 2017; Dalege et al., 2018, 2019). Figure 1 depicts a conceptual representation of the growth principle in the temporal evaluative information ecology.

Our proposed growth principle is supported by systematic reviews of the developmental trajectory of self-evaluations over time. For instance, it is known that self-esteem generally improves through adolescence and early adulthood, but then rapidly declines in older age (Robins and Trzesniewski, 2005). Others have suggested that this rise and fall of favorable self-evaluation coincides with a stark increase in physical and cognitive abilities through early and middle adulthood, as well as new opportunities related to career, financial and relational security, status, and so on Demo, 1992. However, in late adulthood and through old age, these bursts of improvement and opportunity also decline as do favorable self-evaluations. In sum, through processes of reinforcement, learning, and true developmental change, people are likely to improve over time for much of their lives, with decline being common only in older age. The growth principle is unique to the temporal evaluative information ecology because in tem- 
poral comparisons, the target and standard of comparison are not independent. In a social comparison between person $\mathrm{A}$ and person $\mathrm{B}$, the attributes of each are drawn independently from a world of possible attributes that each person can possess; the attributes of person B do not depend on what person A already possesses, and are not a function of any intraindividual processes that are shared between the two. However, when comparing the past and present self over time, this is not the case as the attributes of the present self are a function of the past. Each attribute of the past self has a likelihood of remaining in the present self, and each attribute of the present self is largely influenced by those that already exist in the person. If the growth principle is acting in concert with the diversity and frequency principles, then a new possibility emerges: differences will be negative unless offset by growth (i.e., improvement) over time. We first aimed to test this prediction in a simulation.

\section{Simulating Past and Present Self - Comparisons}

We implemented a simulation of temporal comparison using R. First, we generated a profile for the past self that followed the frequency and diversity principles specified in the EvIE model and follows methods described in Alves et al. (2017a). The simulation randomly assigned positive attributes to the past self from a vector of 100 possible attributes, and negative attributes to the past self from a vector of 150 possible attributes, implementing the diversity principle. Positive attributes were selected to be more prevalent than negative attributes at a rate of approximately $2: 1$, implementing the frequency principle. These two attribute profiles simulate a person's unique attribute set with a subset of positive and negative attributes from a larger pool of possible attributes.

Using the past self as a standard, we then simulated four possible attribute profiles for the present self. In the first no change scenario, we generated a present self that possessed the same number and ratio of positive-to-negative attributes as the past self, except that the attributes themselves could be shuffled into new positions. This simulation of the present self represents someone who has not improved or declined in overall valence of attributes, but has potentially acquired different sets of positive and negative attributes over time. In the second random change scenario, we generated a present self that had a 50 percent chance of losing (keeping) a positive or negative attribute possessed by the past self, or gaining (not gaining) a new positive or negative attribute. This profile represents someone whose growth or decline, in terms of keeping, gaining, or losing positive and negative attributes, happens randomly. The third half growth scenario simulated one aspect of the growth principle, in which there was a higher likelihood of keeping (vs. losing) a positive attribute possessed by the past self, and of gaining (vs. not gaining) a new positive attribute not possessed by the past self. The likelihood of gaining or losing negative attributes remained at 50 percent. Finally, a full growth scenario was simulated that represented the growth principle described previously (see Table 1 and Figure 1). Positive attributes had a high chance of remaining the same across time, and a high chance of emerging anew in the present self. Negative attributes had a low chance of remaining the same, and a low chance of emerging anew. This profile represents how positive attributes are reinforced and learned over time, whereas negative attributes are not (and are even weaned out through learning and punishment).

Next, the simulation determined which attributes were shared between the past and present selves (similarities) and which attributes were unique to the past self (past differences) and which were unique to the present self (present differences). The simulation then selected four attributes at random from the lists of shared and unique attributes for both the past and present selves. Finally, a baseline past and present self attribute profile was generated for each scenario, which represented sampling four attributes from the full list of positive and negative attributes assigned to the past and present selves in that scenario. The baseline profile represents a nonrelative attribute profile, as if a person were to select any four attributes of the target self without focusing on similarities or differences. Each simulation consisted of 1,000 resamples and the focal outcome was the sum of positive and negative attributes for baseline, similarities, past differences, and present differences in each scenario.

Note that this simulation captures just two points in time, as a demonstration of what temporal comparison effects might look like cross-sectionally, given a few different ways the present self may develop from the past self. We do not intend that this simulation be a complete reflection of reality. The true likelihoods that determine how attributes change for individuals over time likely fluctuate over the course of one's life and across situations and life domains (see Studies 6-8 for tests of these boundary conditions). Thus, this simulation is only meant to examine what we could expect the data to look like given some assumptions about how the information ecology looks from one point in time to another when people are focusing on similarities and differences between their past and present selves. Simulations that model how the ecology might deviate from our general assumption (e.g., cognitive decline in old age, bursts of improvement when learning new skills, random fluctuations from day to day, etc) are outside the scope of this paper.

\section{Simulation Results}

Figure 2 shows the simulation results and Table 2 reports the means and standard deviations for each comparison and scenario. For all four scenarios, comparisons based on similarities leads to a more positive outcome compared to comparing differences (Alves et al., 2017a). However, the valence resulting from comparisons based on differences de- 

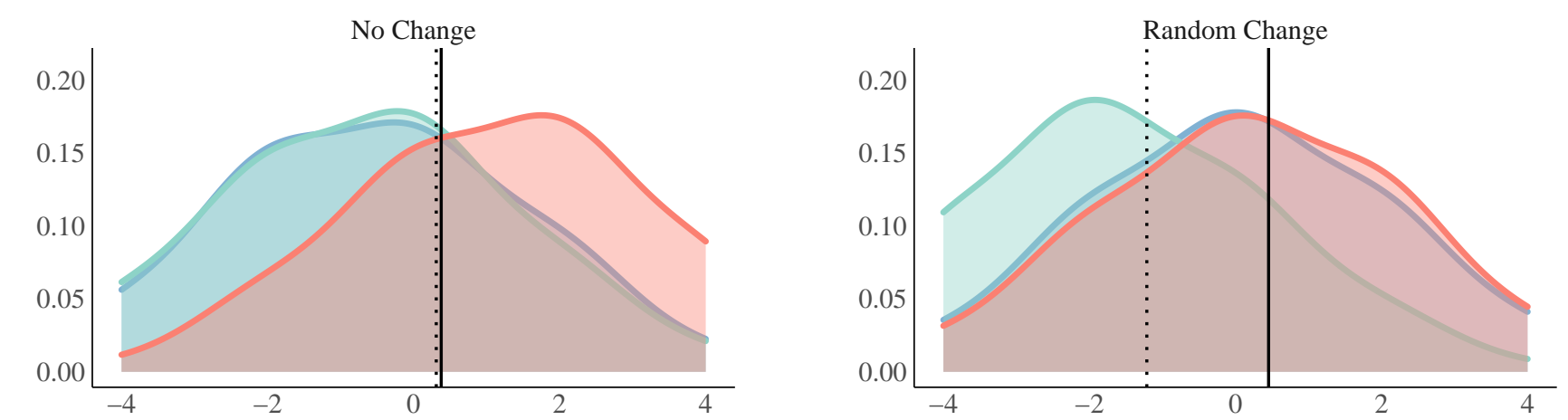

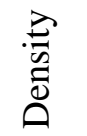
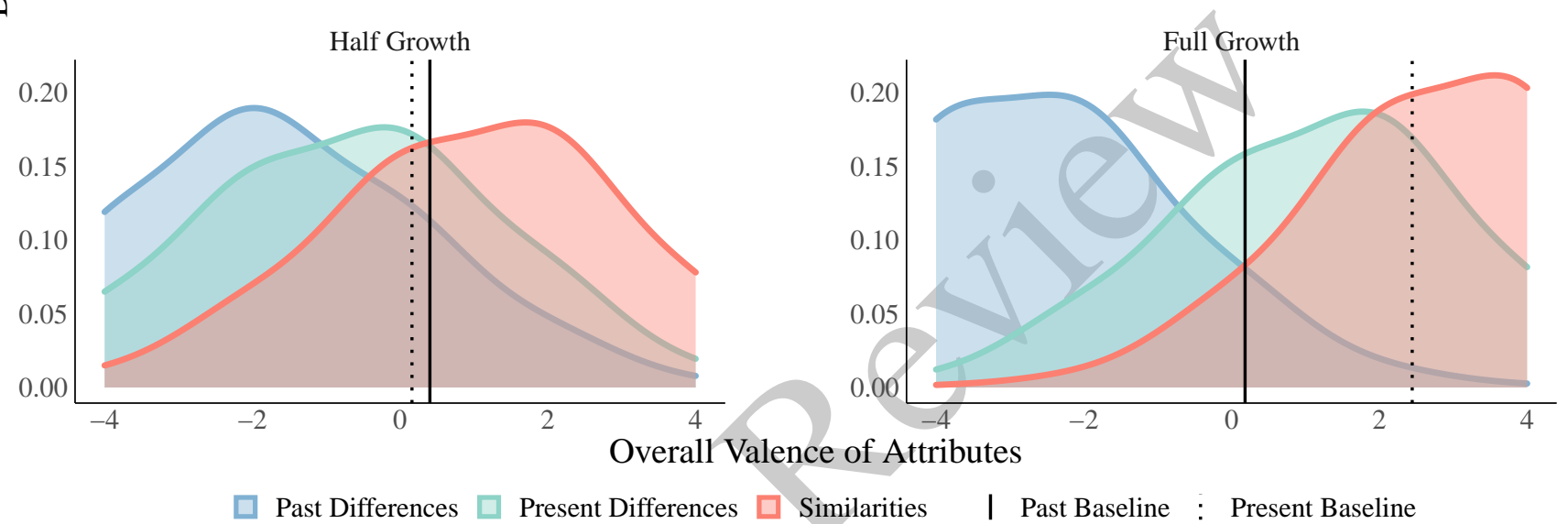

Figure 2

Simulated density (y-axis) distributions of overall valence of attributes in the similarities, present differences, and past differences samples. Solid vertical lines reflect the valence of the baseline past self and dashed vertical lines reflect the valence of the baseline present self.

pends on the growth scenario. When no change in valence has occurred between the past and present selves (i.e., no growth), both past and present differences are more negative than similarities; and each are more negative than the past and present at baseline. When change is random, we see that past differences are more positive than present differences, but almost equal in valence to similarities. At baseline, the past self is more positive than the present self when change is random. In the half-growth scenario, in which positive attributes were likely to be kept or gained, past differences are the most negative, followed by present differences. However, in this scenario the past and present selves at baseline are almost identical. Finally, in the full-growth scenario, in which positive attributes are reinforced and grow, but negative attributes fade and do not grow, we see a similar pattern: past differences are the most negative, followed by present differences. Importantly, this scenario is the only scenario in which the present self is more positive than the past self at baseline.

These simulation results allow us to address the question of where past self disparagement may arise from, as predicted and demonstrated by various motivational accounts of temporal self-appraisal (Wilson and Ross, 2001, 2003). First, we assume that most people, at least those at the age of a typical participant in a psychology experiment, experience life in a way similar to the half or full-growth scenarios. In these cases, evaluations based on shared attributes will always amplify the positivity of the present and past-selves. Thus, when focused on similarities, the self will be rated more positively, whether the present or past is the target being evaluated. This reflects the "common good" phenomenon established previously (Alves et al., 2017a).

Conversely, in the half and full-growth conditions, evaluations based on dissimilarities attenuate the common good effect, but asymmetrically for the present and past-selves. In each case, the attributes unique to the past self are more negative than baseline, and these attributes are are more negative than positive. These simulated effects are consistent with temporal self-appraisal theory, and yet no motivation is required to produce these patterns. Differences will highlight 
Table 2

Mean valence of simulated attribute profiles across scenario and comparison type.

\begin{tabular}{llcccc}
\hline \multicolumn{1}{c}{ Scenario } & \multicolumn{1}{c}{ Comparison } & Mean & SD & LL 95\% CI & UL 95\% CI \\
\hline No Change & Past Differences & -0.81 & 2.39 & -0.96 & -0.67 \\
& Present Differences & -0.99 & 2.40 & -1.14 & -0.84 \\
& Similarities & 1.66 & 2.13 & 1.53 & 1.79 \\
Random Change & Past Differences & 0.11 & 2.53 & -0.05 & 0.27 \\
& Present Differences & -2.00 & 1.95 & -2.12 & -1.88 \\
& Similarities & 0.36 & 2.49 & 0.21 & 0.51 \\
Half Growth & Past Differences & -2.13 & 1.87 & -2.25 & -2.02 \\
& Present Differences & -1.04 & 2.39 & -1.19 & -0.89 \\
& Similarities & 1.49 & 2.17 & 1.35 & 1.62 \\
& Past Differences & -2.80 & 1.38 & -2.89 & -2.72 \\
& Present Differences & 1.61 & 2.07 & 1.48 & 1.74 \\
& Similarities & 2.96 & 1.26 & 2.88 & 3.04 \\
\hline
\end{tabular}

the negativity of the past self, especially when reinforcement is strong for positive attributes and weak for negative ones (i.e., the full-growth principle). Here is the first evidence that disparagement of the past self is not necessarily motivated by the drive for self-enhancement; merely thinking about the past self in terms of differences will exaggerate the negativity of the past self, in an temporal evaluative ecology that follows the growth principle.

Crucially, these simulation results also allow us to address what would be expected from the data when no real growth or change has occurred regarding the valance of attributes. Attributes that are unique to the present and past selves are less positive than each of those selves at baseline (upper left panel, Figure 2). These results suggest that differences will be more negative unless offset by an active growthprinciple. Our simulation then offers a novel insight against which a motivational account of temporal self-appraisal can be tested, as a motivational account would not predict that people would disparage their present-selves to any degree. Instead, the motivational account would predict that the drive to self-enhance would result in unique present self attributes being perceived as highly positive, and possibly even the most positive.

It is worth noting that the random-change scenario creates an outcome that appears unlikely on the surface, but may also reflect how people tend to change when forces that produce growth either disappear (e.g., reinforcement no longer exists) or those forces are not strong enough to counteract true ecological changes (e.g., aging). In the random-change scenario, attributes unique to the past self appear more positive whereas those unique to the present are more negative. Despite a strong motivation to avoid this evaluation of the self over time, it may be unavoidable when ecological forces undermine the growth principle. In the following studies, we will create experimental conditions implemented in the simulation and compare the results against the simulation outcomes.

\section{Experiments on Past and Present Self-Comparisons}

For all studies, we will use consistent terminology in the form of TARGET-COMPARISON to refer to various conditions of temporal appraisals. For instance, we will use the label past differences to describe a condition in which par- 
ticipants evaluate unique attributes of the past self (relative to the present self). Likewise, the term present differences describes a condition in which participants evaluate unique attributes of the present self (relative to the past self). In terms of similarities, we will use past-similarities to describe a condition in which participants evaluate attributes of the past self that are also shared with the present self. And finally, we will use present-similarities to describe a condition in which participants evaluate attributes of the present self that are also shared with the past self.

The EvIE model's assumption, together with the growth component postulated for people over time, leads to three hypotheses. If these hypotheses are supported empirically, we have evidence that temporal self-appraisal follows basic rules of comparison in an information ecology in which positive attributes are more frequent, negative attributes are more diverse, and in which self-growth occurs:

H1: Shared attributes between the past and present-selves (similarities) will be evaluated most positively.

$H 2$ : Unique attributes of the past self (past differences) will be evaluated least positively.

H3: Unique attributes of the present self (present differences) will be evaluated less positively than shared attributes, but more positively than unique attributes of the past self (past differences).

In other words, we need to produce experimental evidence that replicates the basic finding from the simulation studies. We test these hypotheses in all studies by randomly assigning participants to evaluate shared and unique attributes associated with their past or present selves. If evidence for $\mathrm{H} 3$ were to be found, this would be strong evidence against a motivated self-perception account, as people should be motivated to exaggerate the extent to which their present selves have improved. Furthermore, past self disparagement and present self-praise, should be especially apparent when selfenhancement motivation is strong. To test for this prediction from temporal self-appraisal theory, we varied motivation to self-enhance in several experiments. Finally, we examined how changing the information ecology affects selfappraisals. Eight studies were conducted in three parts, each with different aims. In Part One, studies 1-3 test the basic pattern of temporal-self appraisal when participants are randomly assigned to evaluate either differences or similarities of their present or past selves. In Part Two, studies 4-6 manipulate conditions that should promote (e.g., selfenhancement instructions) or inhibit (e.g., self-accuracy instructions) motivation to exaggerate improvement. In Part Three, studies 7 and 8 examine self-appraisals when enhancement motives are held constant, but the information ecology has changed such that growth is less likely.
All data, materials, and analysis code can be found at https://osf.io/3a72e/?view_only= b176262da0cc4d5b90214cf8ce7bdbba. Although no studies were pre-registered, we report all findings from this series of studies with the exception of one, which examined reaction times as opposed to attribute ratings. Moreover, we examined the $p$-curve of our focal tests in each study (Simonsohn, 2015 to determine that this set of studies contains evidential value $(Z=-7.033, p<.001)$ with a mean power of $96 \%$ [85\%, 99\%] across statistical tests. Power considerations are described at the outset of each study. All participants were from the United States, and were recruited from the general population on Amazon's MTurk. This means that our samples are fairly representative of the US population (Burnham et al., 2018) likely limited by their WEIRDness (Western, Educated, Industrialized, Rich, and Democratic) and thus our results may not generalize outside of WEIRD settings.

\section{Part One: The Basic Pattern \\ Study 1: One Year Comparison}

Study 1 was a straight-forward test of the three hypotheses above. We asked participants to evaluate either their past or present selves, a similar procedure used in other temporal self-appraisal research (Haddock, 2004; Wilson and Ross, 2001). Crucially, however, participants either focused on differences or similarities between the present and past. If people are motivated to self-enhance, we should see that past differences are rated most negatively (Wilson and Ross, 2001), but that present differences are also rated most positively. Because past research has not yet compared present self evaluations based on similarities or differences to the past, it is unclear whether this effect will emerge in support of the self-enhancement hypothesis. Alternatively, if people are sampling attributes from the evaluative information ecology where positive attributes are more frequent and similar than negative attributes, then we would expect past differences and present differences to be equally negative and similarities to be equally positive (top left panel, Figure 2). In addition, if the growth principle is correct, and the temporal ecology entails actual improvement, we should expect past differences to be most negative (H2) and present differences to be positive but less so than similarities (H3; bottom right panel, Figure 2).

\section{Method \\ Participants and design}

An a priori power analysis suggested a sample size of $\mathrm{N}$ $=128$ to detect a medium sized effect with $80 \%$ power $(\alpha=$ $.05, \beta=.80, f=.25)$. We aimed for 200 participants but the final sample consisted of 194 adults $\left(M_{\text {age }}=38.58, S D_{\text {age }}=\right.$ $13.38,54 \%$ male) who participated on Amazon MTurk for $\$ 0.50$. After providing consent, participants were randomly assigned to levels in a 2 (Target: Past vs Present) x 2 (Com- 
parison: Similarities vs Differences) between-subjects experiment.

\section{Target manipulation}

In the Past condition, participants were instructed to spend a few moments thinking about "how yourself from last year is related to yourself today." In the Present condition, participants were instructed to spend a few moments thinking about "how yourself today is related to yourself from last year." Participants were then asked to type four words or phrases into separate text boxes that described the target self in terms of similarities or differences.

\section{Comparison manipulation}

In the Similarities condition participants were instructed to describe attributes or characteristics of the target self that are also like the standard, whereas in the Differences condition they were instructed to describe characteristics of the target self that are not like the standard. For example, participants in the Past/Similarities condition were prompted with the question: "How is yourself from last year also like yourself today?"

\section{Measures}

After describing the target self, participants were shown the four attributes they had written previously and were instructed to rate the valence of each one on a 7-point scale (1 $=$ extremely negative, $7=$ extremely positive; $\alpha=.91$ ).

\section{Results}

Figure 3 shows participants' ratings as a function of similarities vs. differences and present vs. past self. Overall, participants rated their self-attributes generally more positive than negative, a one-sample $t$-test comparing average ratings to the midpoint of the valence scale $(4=$ neutral $)$ revealed that participants' self-descriptions were rated positively, $M=4.82, S D=1.97,95 \%$ CI $[4.54,5.10], t(193)=$ $5.80, p<.001$. However, valence ratings were moderated by condition. A two-way ANOVA predicting ratings from Target, Comparison, and the Target $\mathrm{x}$ Comparison interaction revealed a main effect of Target, $F(1,190)=24.76$, $p<.001$, partial $\eta^{2}=0.11$, such that attributes of the present self were rated more positively $(M=5.41, S E=0.17)$ than attributes of the past self $(M=4.20, S E=0.17)$. The effect of Comparison was also significant, $F(1,190)=37.27$, $p<.001$, partial $\eta^{2}=0.16$; participants rated similarities more positively ( $M=5.55, S E=0.17$ ) compared to differences $(M=4.06, S E=0.17)$. These main effects were qualified by a significant interaction between Target and Comparison, $F(1,190)=15.66, p<.001$, partial $\eta^{2}=0.07$. Pairwise comparisons revealed that attributes in the Past Differences condition were rated more negatively compared to all other conditions (Past Similarities: difference $=2.44$, $p<.001$; Present Differences: difference $=2.17, p<.001$; vs. Present Similarities: difference $=2.70, p<.001)$. No other simple effects were significant ( $p s>.63)$.
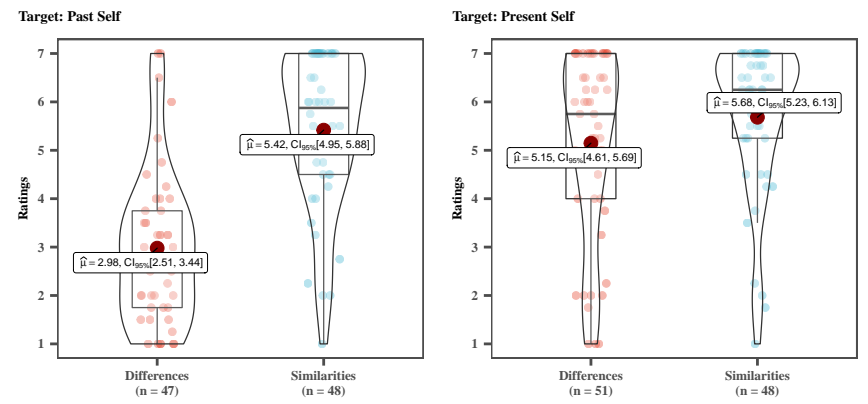

Figure 3

Study 1: Attributes are evaluated positively except when describing how the past self was different than the present self.

\section{Discussion}

These results generally support past research on the socalled 'chump to champ' effect whereby people disparage past selves in order to perceive improvement over time. Indeed, the past self was evaluated more negatively than the present self, but this was only the case when thinking about differences. This effect does not follow from temporal selfappraisal theory, but follows from the present cognitiveecological approach, as stated in $\mathrm{H} 2$. H1 was also supported, as similarities were rated most positively. However, support for motivated self-perception is less obvious when looking at present differences. Participants did not exaggerate the positivity of their present differences, which would be expected if there was a motive to perceive self-improvement.

There was no evidence in this study of an ecological account that would predict differences to be rated more negatively for both past and present-selves (Alves et al., 2017a), as present differences were evaluated as positively as present similarities. This means that $\mathrm{H} 3$ was not supported, as it predicts greater divergence between present differences and similarities. There are two straightforward possibilities for this null effect. First, improvement may be strong enough to overcome the ecological likelihood that differences are negative. This case is present in the simulation data (see Figure 2's lower right-hand panel). Second, a one-year comparison might be not adequate to sample negative differences (which would support H3), or to encourage self-enhancement via exaggerated praise of present differences (which would support the motivated self-perception account).

Motivation may, or may not, be necessary to produce the patterns of means found in Study 1, and it is still unclear from the results whether a cognitive-ecological process (e.g., sampling of negative differences) is occurring. Study 2 aimed to address some of these limitations by instructing participants to consider the past self from ten years ago, which would allow more time for substantial changes to have occurred in one's life. 


\section{Study 2: Ten Year Comparison}

Study 2 aimed to provide participants more opportunity to embellish the differences between their past and present selves by increasing the temporal distance between the two. According to temporal self-appraisal theory, more distance to the past self should translate into greater freedom to disparage the past in service of self-enhancement. If this is true, we might also expect that ten-year's worth of difference between the past and present self also affords participants more opportunity to exaggerate ways the present self has grown and changed for the better. Moreover, we might expect rating of past differences in this study to be more negative compared to Study 1 , given that more temporal distance should lead to greater disparagement.

Adding temporal distance also gives us better opportunity to find support for the ecological process, if one is there. Greater temporal separation between the past and present makes it more likely that participants can perceive the two selves as categorically different, which would prompt sampling of unique attributes.

\section{Method \\ Participants and design}

According to $\mathrm{G}^{*}$ Power, a sample size of 105 would be sufficient to detect the interaction from Study 1 with $80 \%$ power $\left(\alpha=.05\right.$, partial $\left.\eta^{2}=0.07\right)$. We increased our power to $99 \%$ (requiring an $\mathrm{N}$ of 243) and obtained 248 adults $\left(M_{\text {age }}=35.94, S D_{\text {age }}=11.61,57 \%\right.$ male $)$ who participated on Amazon MTurk for \$0.50. After providing consent, participants were randomly assigned to the same betweensubjects conditions as in Study 1. The manipulation was identical except that participants were instructed to consider their past self from 10 years ago.

\section{Measures}

After describing the target self, participants saw the four attributes they had typed previously and rated the valence of each one on a 7-point scale $(1=$ extremely negative, $7=$ extremely positive; $\alpha=.89$ ).

\section{Results}

Figure 4 shows participants' ratings from Experiment 2 again as a function of similarities vs. differences and present vs. past self. Consistent with Study 1, a one-sample $t$-test comparing average valence ratings to the midpoint of the scale $(4=$ neutral) showed that participants rated their selfdescriptions positively, $M=4.99, S D=1.89,95 \%$ CI [4.76, 5.23], $t(247)=8.28, p<.001$. Valence ratings were moderated by condition. A two-way ANOVA predicting ratings from Target, Condition, and the Target $\mathrm{x}$ Condition interaction revealed a main effect of Target, $F(1,244)=40.53$, $p<.001$, partial $\eta^{2}=.14$, such that attributes of the present self were rated more positively $(M=5.65, S E=.14)$ than attributes of the past self $(M=4.29, S E=.15)$. The effect of Comparison was also significant, $F(1,244)=35.25, p<$
.001 , partial $\eta^{2}=.12$, such that similarities were rated more positively $(M=5.58, S E=.14)$ compared to differences $(M=4.36, S E=.14)$. These main effects were qualified by a significant interaction between Target and Comparison $F(1,244)=19.99, p<.001$, partial $\eta^{2}=.07$. As in Study 1 , past differences were rated as more negative compared to all other conditions (Past Similarities: difference $=2.14$, $p<.001$; Present Differences: difference $=2.27, p<.001$; Present Similarities: difference $=2.58, p<.001)$. No other simple effects were significant $(p s>.52)$.
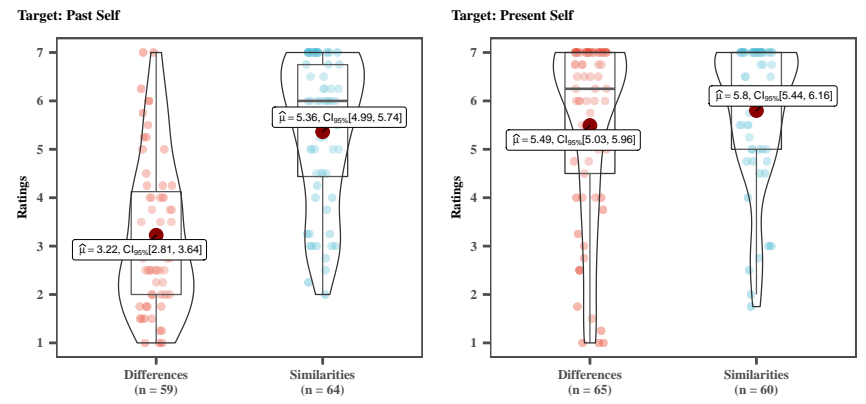

Figure 4

Study 2: Attributes are evaluated positively except when describing how the past self was different than the present self.

\section{Discussion}

These results fully replicate the findings from Study 1. past self differences were evaluated more negatively than any other target/comparison combination, a finding that follows from both the motivational and ecological account. However, we again did not find support for the motivational account when looking at present differences. If participants were motivated to self-enhance, then present differences (i.e., how is the present self different from the past self) would be rated most positively. Instead, what we find is that present differences are statistically indistinguishable from similarities (i.e., how is the present similar to the past self).

This consistent finding suggests a few possibilities. One is that people are not motivated to self-enhance by praising the present self. Perhaps past self disparagement is the easiest and most effective mode of self-enhancement in the context of temporal self-comparisons and thus people do not bother with praising the present self's growth. Another possibility is that motivation does not factor into the consequences of temporal comparisons as strongly as previously thought. Indeed, the findings from Studies 1 and 2 most closely resemble the findings from the simulation study, in which ecological factors are producing an accurate perception of self-positivity and growth. Past differences are negative because comparisons in a standard ecology based on differences are negative; that is, Alves et al.'s (2017a) common-good phenomenon. However, present differences might be buffered from this effect because people are actually improving over time. These 
two effects cancel out, making present differences equally positive as similarities. A third possibility is that the effect for comparison mode (i.e., similarity vs. differences) in the present self target condition is not located in the rating extremity, but in the number of attributes generated. That is, participants may rate the first four attributes equally positive, but they may have more positive attributes available for the similarity compared to the differences. We also address this possibility in Study 3.

However, in the simulation studies, present differences were still relatively less positive when compared to present similarities, even when large improvements had occurred (e.g., Figure 2, bottom right panel). We do not find evidence for this (our stated H3) in Studies 1 and 2, suggesting that people may indeed be nudging their present differences in a positive direction out of a drive to self-enhance. Alternatively, it is possible that present differences are evaluated more positively than would be expected from the simulation studies because they are being made relative to the past self, but not being calibrated against present self similarities. Study 3 addresses these open possibilities.

\section{Study 3: Comparison Within-Subjects}

Social comparisons involve testing hypotheses about similarities and differences between targets and standards (Mussweiler, 2003), and the two are often intertwined as bringing to mind similarities can also make differences accessible (Medin et al., 1993). In Studies 1 and 2, we manipulated comparison mode between participants; they either considered only differences or only similarities. To find evidence for H3, participants may need to evaluate differences as well as similarities between past and present selves.

Under the ecological framework, present differences should appear relatively less positive when one has also brought to mind present similarities, as this would be the accurate perception given the simulation study results. Under the motivational framework, however, present differences should be evaluated more positively when compared to present similarities, as this would signal self-improvement. Study 3 examines the evaluative asymmetry apparent from Studies 1 and 2, but using a mixed-design. Participants brought to mind both similarities and differences of either their past or present selves.

We additionally modified the design in order to more thoroughly test the motivational account. First, participants were allowed to generate as many attributes as they wanted up to a maximum of 20 , giving them the chance to generate many more negative past differences and many more positive differences to maximize self-improvement. Second, we measured subjective self-continuity to the past self to ensure that differences in evaluations across the target and comparison conditions were not due to differences in the extent to which participants felt more or less connected to who they were in the past. If past self derogation in this study is due to participants distancing from the past self in service of selfenhancement, we should find that more negative evaluations of past differences is associated with lower self-continuity (Wilson and Ross, 2001). We used the time difference of five years to the past selves.

\section{Method}

\section{Participants and design}

Participants were 400 adults $\left(M_{\text {age }}=37.37, S D_{\text {age }}=\right.$ 11.23, 61\% male) who participated on Amazon MTurk for $\$ 0.70$. After providing consent, participants were randomly assigned to conditions in a 2 between (Target: Past vs Present) x 2 within (Comparison: Similarities vs Differences) mixed-design. Note that a sample size of 400 is well above the required sample needed to detect the interaction effect found in Studies 1 and 2 in this mixed (between/within) design with $80 \%$ power.

\section{Manipulation}

In the Past condition, participants were instructed to take a few moments to compare their past self from five years ago to their present self today by focusing specifically on attributes or characteristics of their past self. In the Present condition, the instructions were identical except participants were instructed to think about attributes of their present self, relative to their past self. Then all participants were instructed to think about both similarities and differences between the target and standard self and to type as many similarities and differences between the two selves as possible in a series of 20 text boxes for each type of comparison. Instructions were clear that participants could type as many attributes or characteristics as they would like, that they did not have to fill all boxes, and that their lists of similarities and differences could be of different sizes.

\section{Measures}

After describing similarities and differences of the target self, participants were asked to evaluate the overall valence of each list using a 7 -point scale $(1=$ very negative, 7 = very positive), resulting in an overall rating for similarities and an overall rating for differences. Participants then used a 7-point scale ( $1=$ strongly disagree, $7=$ strongly agree $)$ to indicate their feelings of past self continuity (e.g., I feel connected with my past; I feel connected with who I was in the past; $\alpha=.84)$. Finally, participants completed demographics, read a debriefing statement, and exited the study.

\section{Results}

On average, participants listed $4.50(S D=2.30)$ similarities and $4.40(S D=2.22)$ differences. Figure 5 shows participants' ratings for their chosen attributes across Target and Comparison conditions. Consistent with Studies 1 and 2, a one-sample $t$-test comparing average valence ratings to the midpoint of the scale $(4=$ neutral) showed that overall, participants rated their attributes positively, $M=5.14$, $S D=1.20,95 \%$ CI $[5.02,5.26], t(397)=18.87, p<.001$. 
However, ratings were moderated by condition. We tested a hierarchical linear mixed-effects model with overall ratings as the outcome, Target and Comparison included as predictors in Step 1, and the Target $\mathrm{x}$ Comparison interaction included in Step 2. A random-intercept was included for participant to account for the repeated evaluations. The main effect of Target was not significant, $b=-0.10, t(398)=$ $-0.80, p=.43$, whereas the effect of Comparison was, $b=-.54, S E=.10,95 \%$ CI $[-.74,-.34], t(399)=-5.34$, $p<.001$. Similarities were rated more positively $(M=5.41$, $S E=.08)$ compared to differences $(M=4.87, S E=.08)$. This main effect was qualified by a significant interaction between Target and Comparison, $b=-.51, S E=.20$, $95 \%$ CI $[-.90,-.11], t(398)=-2.52, p=.01$. Past differences were rated less positively compared to all other conditions (Past similarities, difference $=.78, p<.001$; Present similarities: difference $=.62, p<.001$; Present differences: difference $=.35, p=.04)$. Present differences were also rated less positively than past similarities (difference $=.43, p=.01$ ) but were not significantly different from present similarities (difference $=.27, p=.08$ ). Past and present similarities were not significantly different (difference $=.16, p=.32$ ).
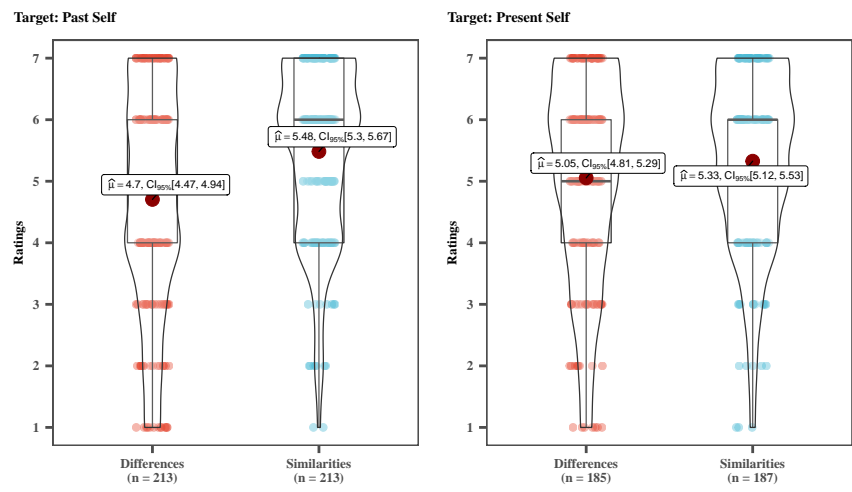

Figure 5

Study 3: Attributes are evaluated positively except when describing how the past self was different than the present self.

Past self continuity did not significantly differ across Target, $t(361.41)=-.04, p=.97$, and the predicted interaction between Target and Comparison was virtually unchanged when including past self continuity as a covariate in the model, $b=-.51, S E=.20,95 \%$ CI $[-.90,-.11]$, $t(398)=-2.53, p=.01$. Moreover, continuity was not significantly correlated with past self evaluations, whether evaluations were based on differences, $r(211)=.10, p=.15$, or similarities, $r(211)=.07, p=.30$. Subjective feelings of (dis)continuity did not seem to factor into participants' evaluations.

\section{Discussion}

Study 3 broadly replicates Studies 1 and 2 in that past differences were evaluated less positively than both past and present similarities. This finding would follow from the motivational account of self-enhancement. However, Study 3 adds new evidence that does not support this motivational account. First, we find that present differences in this mixeddesign were evaluated less positively than past similarities, although not significantly different than present similarities. Although the effect is small, this difference is more consistent with the full growth simulation results (bottom right panel, Figure 2) than with a motivational account, which would predict that present differences would be rated most positively. Second, we found that controlling for past self continuity did not account for the effect of Target and Comparison, and continuity was not significantly associated with past self evaluations. Distancing of the past self from the present is said to be a fundamental mechanism driving the temporal self-appraisal effect found in prior research (Wilson and Ross, 2001). And yet, we do not find strong evidence for this mechanism here.

Rather, it seems as though people have a fairly accurate perception of their present and past attributes in an ecology that favors positive over negative attributes, but in which actual improvement is likely occurring. Nevertheless, when given the choice, or when conditions are right, participants may be motivated to exaggerate these accurate perceptions in service of self-enhancement. In Studies 1-3, we did not compare participants across conditions that encourage or discourage self-enhancement. Studies 4-6 address this limitation.

\section{Part Two: Examining Motives as a Moderator}

In the next three studies, we aim to falsify the cognitiveecological explanation of the temporal evaluative asymmetry found in Studies 1-3 by inducing self-enchantment motives in different ways. If motivation to enhance the present self explains the past self disparagement effects found previously, then these effects should be exacerbated by motivation to self-enhance, and attenuated when those motivations are not as strong. Moreover, self-enhancement motives should produce stronger present self praise when participants are focused on unique attributes of the present self (differences), because exaggerating present differences would be a viable self-enhancement strategy . However, if we fail to find moderation of the temporal evaluative asymmetry-that is, if we consistently obtain null effects of motivation-this would be evidence in favor of our cognitive-ecological explanation. Thus, although significant moderation by motivation would falsify our current theory, we rather expect to find null effects for motivation. We use Bayesian approaches to test for null effects.

\section{Study 4: Subjective Distance}

In the previous study, we measured the extent to which participants felt close, or connected, to their past-selves. Al- 
though motivation is expected to drive people to distance from their past-selves in order to see improvement, we did not find evidence that this occurred. However, given that we measured self-continuity in Study 3, it is possible that there were other variables prevented effects that would support the motivational account. Thus, in Study 4, we manipulated subjective distance to the past self; a paradigm that has been used reliably in past research to induce derogation of the past self in favor of self-enhancement (Wilson and Ross, 2001). If the motivational account is the best explanation for the asymmetry found previously, participants who perceive greater distance to the past self should feel more comfortable derogating that past self in order to self-enhance. However, if the cognitive-ecological account is more suited to the data, subjective distance should not matter as the resulting asymmetry would arise from accurate perceptions of past and present attributes.

\section{Method}

\section{Participants and design}

We recruited 200 adults $\left(M_{\text {age }}=38.78, S D_{\text {age }}=11.89\right.$, $51 \%$ male) on Amazon MTurk who were compensated $\$ 0.50$. Sample size was adequate to detect the two-way interactions found consistently in Studies 1-3 with $80 \%$ power, but falls short of what would be required to detect a mediumsized three-way interaction at that same level of power (see Simonsohn, 2015). We discuss this limitation later.

After providing consent, participants were randomly assigned to levels in a 2 (Distance: Near vs Far) x 2 (Target: Past vs Present) x 2 (Comparison: Similarities vs Differences) between-subjects experiment. In the Distance conditions, participants were told that they would be comparing their present and past self from five years ago. They were then shown a timeline to help them visualize the relation (distance) between their present and past (Figure 6).

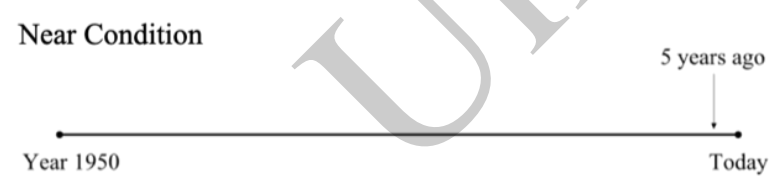

Far Condition

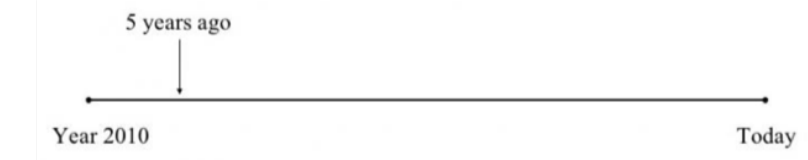

Figure 6

Study 4: Timelines used to manipulate subjective distance to the past self.

In the Near condition, the timeline stretched from the "Year 1950" on the left to "Today" on the right. An arrow was drawn which pointed to a location on the timeline very close to the label for "Today" and was labeled with the text "5 Years Ago." In the Far condition the timeline stretched from the "Year 2010" on the left and "Today" on the right. The arrow labeling "5 Years Ago" was thus placed on the timeline much further away from the label for "Today." A three-item manipulation check followed the distance manipulation (e.g., "How close do you feel to who you were 5 years ago?" $1=$ not at all close; 5 = very close).

Next, participants were randomly assigned to the same Target and Comparison conditions as in Studies 1 and 2 and were instructed to type four attributes of the target self in four separate text boxes. The relevant timeline also appeared on the top of the page and participants were encouraged to use the timeline as they described the target self.

\section{Measures}

After describing the target self, participants were shown the four attributes they had typed previously and were instructed to rate the valence of each one on a 7-point scale (1 = extremely negative, $7=$ extremely positive; $\alpha=.85$ ). After completing the tasks, participants read a debriefing statement and exited the study.

\section{Results}

The manipulation was not successful, at least as measured by the three-item manipulation check. Participants in the Far condition felt as close to their past selves $(M=2.99$, $S D=1.01)$ as participants in the Near condition $(M=3.04$, $S D=1.09$ ). Nevertheless, we proceeded to test whether the manipulation had any influence on the evaluative asymmetry found in Studies 1-3. Consistent with previous studies, a one-sample $t$-test comparing average ratings to the midpoint of the valence scale $(4=$ neutral) revealed that participants' self-descriptions were rated positively, $M=5.26$, $S D=1.74,95 \%$ CI $[5.02,5.51], t(199)=10.25, p<.001$. However, valence ratings were moderated by condition. A three-way ANOVA predicting ratings from Target, Comparison, Distance and all two and three-way interactions revealed a main effect of Target, $F(1,192)=17.91, p<.001$, partial $\eta^{2}=.08$, such that attributes of the present self were rated more positively $(M=5.73, S E=.15)$ than attributes of the past self $(M=4.81, S E=.15)$. The effect of Comparison was also significant, $F(1,192)=26.38, p<.001$, partial $\eta^{2}=.11$, such that similarities were rated more positively $(M=5.82, S E=.15)$ compared to differences $(M=4.71$, $S E=.15)$. There was no main effect of Distance on ratings, $p=.71, B F(10)=.17$.

The main effects were qualified by a significant two-way interaction between Target and Comparison, $F(1,192)=$ 24.24, $p<.001$, partial $\eta^{2}=.10$. No other interactions were significant $(p s>.62, B F(10) s<.17$ ) so we only tested simple effects from the Target $\mathrm{x}$ Comparison interaction averaging over the distance conditions. Past differences were rated as more negative compared to all other conditions (vs. Present Differences: difference $=1.98, p<.001$; vs. Past 
Similarities: difference $=2.17, p<.001$; vs. Present Similarities: difference $=2.02, p<.001$ ). No other simple effects were significant ( $p s>.76$ ). The Target x Comparison interaction, collapsed across distance conditions, is depicted in Figure 7.
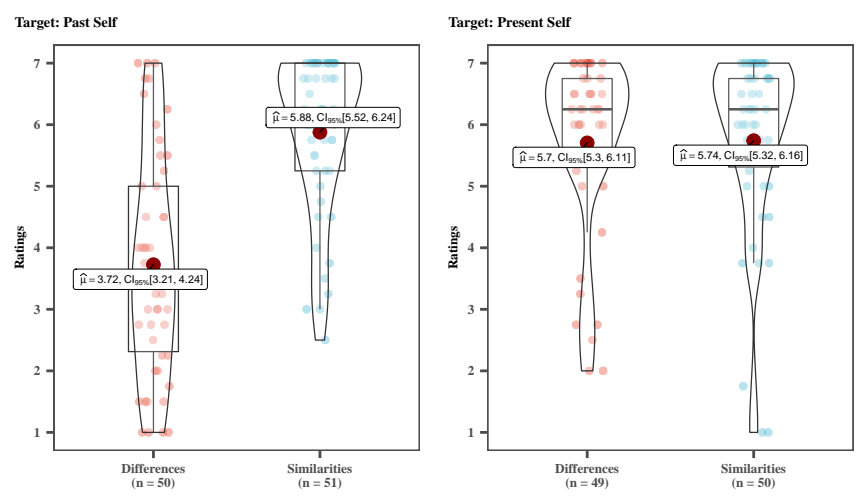

Figure 7

Study 4: Self-attributes are overwhelmingly positive except when describing how the past self was different than the present self. Subjective distance did not influence ratings so figure is collapsed across this factor.

\section{Supplemental analyses}

We also tested a regression model in which the distance condition variable (dichotomous) was replaced with participants' self-reported distance scores (continuous). The threeway interaction was not significant, and the evidence favored the null hypothesis, $\beta=-.14, S E=.41, p=.67$, $B F(10)=.16$, suggesting that self-reported subjective closeness did not moderate the Target $\mathrm{x}$ Comparison interaction. The two-way interaction between Target and Comparison remained significant when treating subjective closeness as a covariate, $F(1,195)=26.07, p<.001$, partial $\eta^{2}=.11$.

\section{Discussion}

As in previous studies, past differences were evaluated more negatively than all other comparisons. Similar to Study 4, this asymmetry was not influenced by manipulated or measured subjective distance to the past self. Bayesian analyses suggested very strong support for the null hypothesis when subjective distance was included as a moderator in the models. Increased distance did not afford participants more opportunity or drive to embellish past or present differences in a way that would be self-enhancing. Instead, we argue that focusing on differences brings to mind negative attributes; but because the self tends to improve over time, it is only the past differences that are evaluated negatively. One potential limitation of Study 4 is that our small sample size simply could not allow us to detect the true effect of subjective distance in this study. But given that no two-way interactions including subjective distance were significant (an effect that would be properly powered with our sample size, given it were medium-sized), we are confident that subjective distance-operationalized this way-is not a meaningful moderator in this study. Another limitation is that the distance manipulation may have been unsuccessful, as participants in both Distance conditions reported the same degree of closeness to their past selves. In Study 5, we aimed to conceptually replicate Study 4 by directly manipulating selfenhancement motives, and by increasing our sample size.

\section{Study 5: Self-Enhancement vs. Self-Accuracy}

Another factor that should influence temporal selfappraisal is whether people are focused on self-enhancement versus self-accuracy. If people are instructed to report the most accurate evaluation of themselves, we should expect to see a pattern of temporal self-appraisal that fits the simulation study results-most negative past differences, slightly less positive present differences, and mostly positive similarities. If, however, people are instructed to present the best possible evaluation of themselves, we should see that past differences are most negative and present differences are most positive, as this pattern would highlight the greatest degree of improvement. At the very least, past differences should be more negative under instructions to self-enhance compared to instructions to be accurate, as the self-enhancement motive should lead to greater past self disparagement (Wilson and Ross, 2001). Study 5 tested these competing hypotheses.

\section{Method}

\section{Participants and design}

Participants were 300 adults $\left(M_{\text {age }}=37.16, S D_{\text {age }}=\right.$ $11.02,53 \%$ male) who participated on Amazon MTurk for $\$ 0.50$. Although this sample size still falls short of what would be required to detect a medium-sized three-way interaction at $80 \%$ power, we feel that we gain some power over Study 4 with the slight increase in sample size and a more direct manipulation of the self-enhancement motive. Thus, we feel that this study is a stronger test of the motivational account.

After providing consent, participants were randomly assigned to the conditions of a 2 (Motive: Enhancement vs Accuracy) x 2 (Target: Past vs Present) x 2 (Comparison: Similarities vs Differences) between-subjects experiment. In the Enhancement condition, participants were instructed to "imagine that you are applying for a job and are being asked to create a profile of your personal attributes and characteristics." They were told that their personal profile would be the first thing the hiring committee would see and so they should try to create the best personal profile that they could. They were also told that each member of the hiring committee would see their profile. These instructions were meant to encourage participants to engage in self-enhancement.

In the Accuracy condition, participants were instructed to "imagine that you are doing a self-awareness exercise and are being asked to create a profile of your personal attributes and characteristics." They were told that their per- 
sonal profile would determine how the self-awareness exercise would look and so they should try to create the most accurate personal profile that they could. They were also told that they would be the only person who would see their profile. These instructions were meant to reduce the drive for self-enhancement relative to the Enhancement condition. After being assigned to the Motive conditions, participants were assigned to the same Target and Comparison conditions as in previous studies (participants considered a self from one year ago). Participants were instructed to type four attributes of the target self in four separate text boxes.

\section{Measures}

After describing the target self, participants saw the four attributes they had typed previously and rated the valence of each one on a 7-point scale ( $1=$ extremely negative, $7=$ extremely positive; $\alpha=.93)$. After completing the tasks and measures, participants read a debriefing statement and exited the study.

\section{Results}

Participants' attributes were evaluated positively, $M=$ $5.21, S D=1.92,95 \%$ CI $[4.98,5.42], t(299)=10.90$, $p<.001$. However, valence ratings were moderated by condition. A three-way ANOVA predicting ratings from Target, Comparison, Motive and all two and three-way interactions revealed a main effect of Target, $F(1,292)=70.86$, $p<.001$, partial $\eta^{2}=.19$, such that attributes of the present self were rated more positively $(M=5.94, S E=.13)$ than attributes of the past self $(M=4.42, S E=.13)$. The effect of Comparison was also significant, $F(1,292)=77.64$, $p<.001$, partial $e t a^{2}=.20$, such that similarities were rated more positively ( $M=5.94, S E=.13$ ) compared to differences $(M=4.42, S E=.12)$. There was no main effect of Motive on ratings, $F(1,292)=.11, p=.74, B F(10)=.19$.

The main effects were qualified by a significant two-way interaction between Target and Comparison, $F(1,292)=$ $31.20, p<.001$, partial $\eta^{2}=.09$. No other two-way interactions were significant $(p s>.16, B F(10)<.51)$ nor was the three-way interaction $(p=.90, B F(10)=.13)$, so we only tested simple effects from the focal Target $\mathrm{x}$ Comparison interaction.

Past differences were evaluated more negatively compared to all other conditions (vs. Past Similarities: difference $=$ 2.53, $p<.001$; vs. Present Differences: difference $=2.53$, $p<.001$; vs. Present Similarities: difference $=3.04$, $p<.001)$. Present differences (difference $=.51, p=.06$ ) and past similarities (difference $=.51, p=.06$ ) were each rated less positively than present similarities, but the effects were small and only bordering on the significance cutoff of $p=.05$. The Target $\mathrm{x}$ Comparison interaction, collapsed across the motive conditions, is depicted in Figure 8.

\section{Supplemental analyses}

As in Study 4, we also measured closeness to the past self with three items (e.g., "How close do you feel to who you
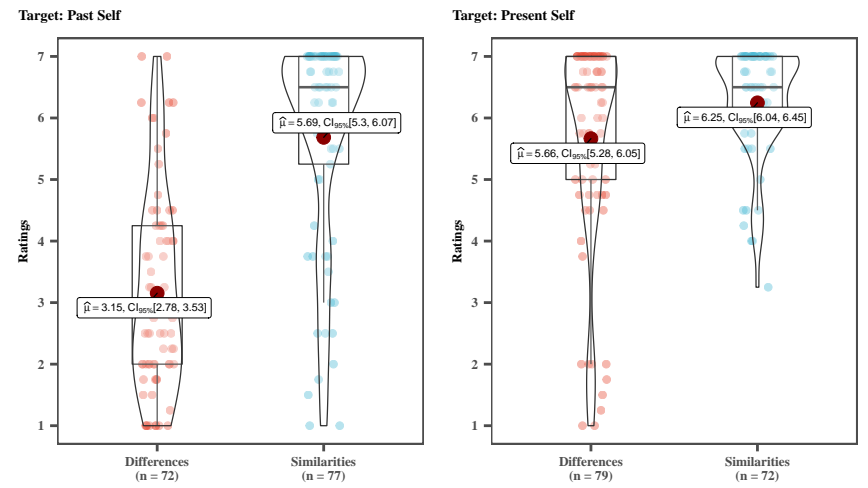

Figure 8

Study 5: Self-attributes are overwhelmingly positive except when describing how the past self was different than the present self. Activating different motives did not influence ratings so figure is collapsed across this factor.

were one year ago?" $1=$ not at all close; 5 = very close) except now we measured it at the end of the study. A two-way ANOVA with Target, Comparison, and the Target $x$ Comparison interaction as factors was used to test whether closeness differed across conditions. As would be expected, participants felt further from their past selves in the Differences condition $(M=3.00, S E=.08)$, compared to the Similarities condition $(M=3.89, S E=.08), F(1,296)=58.56$, $p<.001$, partial $\eta^{2}=.16$. Closeness did not differ significantly across the Target conditions, $F(1,296)=.15, p=.70$, and the interaction was not significant, $F(1,296)=1.89$, $p=.17$.

Finally, treating closeness as a continuous predictor in a Target $\mathrm{x}$ Comparison $\mathrm{x}$ Closeness interaction did not reveal a significant result, $\beta=-.04, S E=.34, t(292)=.20, p=.84$, $B F(10)=.16$. Moreover, including closeness as a covariate did not have a strong influence on the Target $\mathrm{x}$ Comparison interaction, which remained significant, $F(1,291)=30.04$, $p<.001$, partial $\eta^{2}=.09$.

\section{Discussion}

Once again, past differences were evaluated most negatively compared to all other target/comparison combinations. This asymmetry was not influenced by the activation of selfenhancement or self-accuracy motives, as the Bayes factors for the two and three-way interactions including this variable were strongly in favor of the null hypothesis. Of course, it is possible that this manipulation was not strong enough to influence participants' ratings, but when considered alongside Studies 1-4, it seems plausible that motivation is not strongly factoring into these temporal self-appraisal processes. Given that activating different motives, similar to how we did here, has shown to influence the magnitude of the temporal selfappraisal effect (Wilson and Ross, 2001), we would have 
expected at least a small moderation effect to emerge. But statistically, and descriptively, the patterns of means across the two Motivation conditions in Study 5 appear to be almost identical. Crucially, past differences are not more negative, and present differences are not more positive, in the self-enhancement condition as would be expected if selfenhancement were driving these effects.

Although it appears from the studies so far that selfenhancement motives are not fundamental to temporal selfappraisals as previously thought, it is possible that our measures and manipulations have been ineffective. It may be the case that self-enhancement via past self derogation is such an ingrained process that it happens almost inevitably, even despite variation in temporal distance, subjective distance, and activation of different motives. As long as the self is the target, the drive to derogate the past self may trump situational factors that would otherwise influence appraisals. This seems unlikely, as past research has indeed found that situationally primed and measured variables moderate the temporal selfappraisal effect. But to put the issue to rest, we designed Study 6 as a final test of the motivational account by changing the evaluative target to an acquaintance, rather than the self.

\section{Study 6: Evaluating an Acquaintance}

People are less likely to derogate others' past selves (Wilson and Ross, 2001) presumably because the motivation to derogate the past self of another person should be low. There would be little advantage for the self to see others as improving over time and in fact, one could imagine that misperceiving others as better than they really are could serve as a disadvantage; the negative consequences of trusting in nonexistent positive attributes and abilities of others could be large. However, if temporal appraisals are designed to build accurate perceptions of stability and change in the self and others over time, and we assume that ecological processes (frequency, diversity, and growth) underlie those appraisals, then we should expect temporal appraisals of others to follow the same pattern as temporal appraisals of the self. That is, if others possess more positive than negative attributes, and typically improve at the same rate as oneself, then the evaluative asymmetry found in Studies 1-5 should be mimicked when evaluating others. Study 6 tests for this pattern by simply changing the target of evaluation from the self to an acquaintance.

\section{Method}

\section{Participants and design}

Participants were 199 adults $\left(M_{\text {age }}=33.50, S D_{\text {age }}=\right.$ 7.81, 58\% male) who participated on Amazon MTurk for $\$ 0.50$. This sample size allowed us to detect a similarly sized interaction effect as obtained in previous studies with $80 \%$ power $(\alpha=.05)$. After providing consent, participants were randomly assigned to the same 2 (Target: Past vs Present) x 2 (Comparison: Similarities vs Differences) between-subjects conditions as before. However, participants in this study were told that we were interested in how they think about others, and were asked to bring to mind an acquaintance that they had known for at least one year. Participants then wrote the name of that person in a text box, indicated the duration of the relationship to that acquaintance in months, and generated four attributes consistent with the conditions they were assigned to.

\section{Measures}

After describing the acquaintance, participants saw the four attributes they had generated and rated the valence of each one on a 7-point scale ( $1=$ extremely negative, $7=$ extremely positive; $\alpha=.85$ ). After completing the tasks and measures, participants read a debriefing statement and exited the study.

\section{Results}

Twenty-six participants did not follow instructions to describe an acquaintance that they had known for more than one year, so these participants were excluded from analyses. The final sample consisted of 173 adults $\left(M_{\text {age }}=33.84\right.$, $S D_{\text {age }}=9.71,59 \%$ male). On average, participants had known their acquaintance for 4.05 years $(S D=4.16)$. Participants' evaluations of their acquaintance's attributes were positive, $M=5.18, S D=1.73,95 \%$ CI [4.92, 5.44], $t(171)=8.95, p<.001$. But consistent with prior studies, valence ratings were moderated by condition. A twoway ANOVA predicting ratings from Target, Comparison and the Target $\mathrm{x}$ Comparison interaction revealed an effect of Target, $F(1,168)=17.77, p<.001$, partial $e^{2} a^{2}=.09$, such that present attributes of the were rated more positively $(M=5.62, S E=.16)$ than past attributes $(M=4.62$ $S E=.17)$. The effect of Comparison was also significant, $F(1,168)=29.58, p<.001$, partial $e t a^{2}=.14$, such that similarities were rated more positively $(M=5.76, S E=.16)$ compared to differences $(M=4.48, S E=.17)$.

The main effects were qualified by a significant, but small, two-way interaction between Target and Comparison, $F(1,168)=6.29, p=.01$, partial $e t a^{2}=.03$. Past differences were evaluated more negatively compared to all other conditions (vs. Present Differences: difference $=1.59, p<$ .001 ; vs. Past Similarities: difference $=1.87, p<.001$; vs. Present Similarities: difference $=2.29, p<.001$ ). Present differences were also evaluated more negatively than present similarities although the effect was small (difference $=.70$, $p=.05)$. No other simple effects were statistically significant $(p s>.22)$. The interaction is depicted in Figure 9.

\section{Supplemental Analyses}

We also tested whether the duration of knowing the acquaintance influenced the temporal appraisal effect. When including Duration as a covariate in the ANOVA from above, the interaction between Target and Comparison became stronger, $F(1,164)=8.11, p=.005$. Moreover, in- 

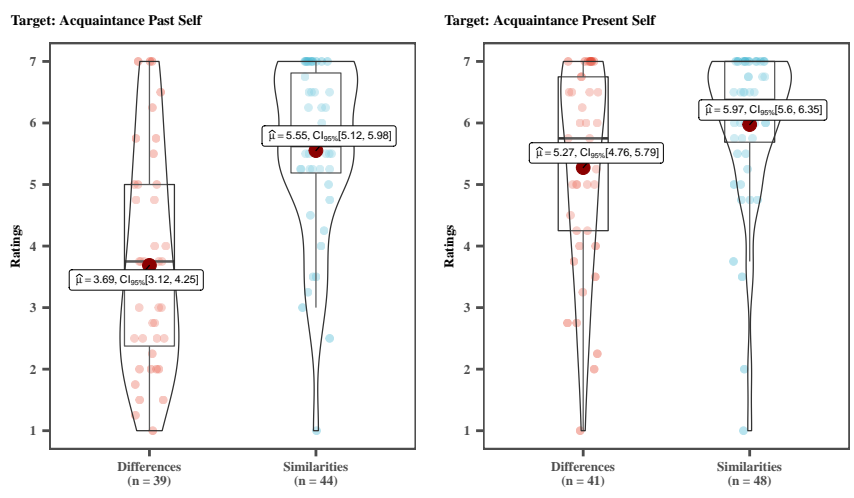

\section{Figure 9}

Study 6: Attributes of an acquaintance are overwhelmingly positive except when describing how the acquaintance was different in the past.

cluding Duration as a third predictor of ratings in a Target $\mathrm{x}$ Comparison $x$ Duration interaction did not reveal a significant effect, beta $=.01, S E=.01, t(161)=.04, p=.97$.

\section{Discussion}

Study 6 reveals that past differences of an acquaintance are also evaluated negatively compared to all other target/comparison pairs. This finding would be surprising under a motivational account of temporal appraisal effects, and indeed, it contradicts prior results (Wilson and Ross, 2001). One explanation of these findings is that participants were still motivated to enhance the acquaintance in a way that would reflect positively on themselves, something akin to basking in reflected glory (Cialdini et al., 1976). But this alternative is weakened by the fact that the duration of the relationship to the acquaintance did not influence or moderate the evaluative asymmetry. If participants were motivated to enhance others who would reflect positively on themselves, it would be reasonable to assume that this drive would be stronger as the duration of the relationship increased, as longterm relationships would likely have a stronger influence on one's own identity.

The motivational account is also weakened by the fact that present differences were evaluated slightly less positively than present similarities. If participants were motivated to bask in the reflected positivity of an acquaintance, then they should exaggerate positive present differences as well as negative past differences. Instead, the pattern of results looks very similar to the results found in Studies 1-5 when participants evaluated themselves. Taken together, the studies so far do not offer strong support for a motivated self-perception account of temporal self-appraisals. Instead, the results are consistent with cognitive-ecological processes that give rise to accurate perceptions. Studies 7 and 8 move away from testing motivational factors and instead focus on finding ev- idence that ecological processes influence the asymmetry in temporal self-appraisals.

\section{Part Three: Examining the Ecology as a Moderator}

\section{Study 7: Physical Attributes}

Our explanation of the temporal self-appraisal effects found in the last six studies is that positive attributes are more prevalent and less diverse than negative attributes (Alves et al., 2017b, 2019, and that the self improves over time, which creates an asymmetry in temporal self-appraisals. Past differences are more negative than similarities, but present differences are not. Although there was some evidence that present differences were evaluated more negatively than similarities, the effects were rather weak. However, we noted that these effects-weak as they are-do not support a motivated selfperception, as present differences should be evaluated positively so as to enhance the self. Instead, we suspect that these evaluations are accurate: the present self has the benefit of improvement, effectively blocking the probabilistic necessity that present differences would be negative under the frequency and diversity principles (Alves et al., 2017a).

Thus, one way to test whether motivation is driving the effects found previously, or whether it is an accurate perception, is to ask participants to evaluate aspects of themselves that are not likely to improve at all stages of life, and may even begin to decline past middle age, namely their physical attributes. When people are asked to bring to mind these attributes, we should not expect to see the same asymmetry found in previous studies if those findings are due to cognitive-ecological perceptions. Under the cognitiveecological model, we should find a main effect, such that differences are evaluated more negatively than similarities. Conversely, under the motivated self-perception model, people should trick themselves into self-enhancement by exaggerating negative past differences and positive present differences. Thus, Study 7 created an information ecology that implies decline not growth, and allows thereby to provide evidence for a cognitive-ecological account.

\section{Method \\ Participants and design}

Participants were 303 adults $\left(M_{\text {age }}=34.80, S D_{\text {age }}=\right.$ $10.17,50 \%$ male) who participated on Amazon MTurk for $\$ 0.50$. As before, this sample size allowed us to detect a similarly sized interaction effect as found consistently across previous studies. After providing consent, participants were randomly assigned to the same 2 (Target: Past vs Present) x 2 (Comparison: Similarities vs Differences) between-subjects conditions as prior studies. However, participants in this study were told that we were "interested in how people think about physical aspects of themselves, such as their physical characteristics, fitness, health, and so on." Participants described the target self by typing four physical attributes in separate text boxes. 


\section{Measures}

After describing themselves, participants were shown the four attributes they had generated and were instructed to rate the valence of each one on a 7-point scale $(1=$ extremely negative, $7=$ extremely positive; alpha $=.83$ ). After completing the tasks and measures, participants read a debriefing statement and exited the study. Two research assistants blind to condition and hypotheses first coded each attribute to ensure adherence to the study instructions $(1=$ physical attribute, $0=$ non-physical attribute, $-99=$ unsure). Agreement between raters was high $(\kappa=.80, z=27.93, p<.001)$. We removed attributes that did not adhere to the instructions (i.e., were not coded by both raters as physical attributes) and created an average evaluation for the remaining attributes using participants' own evaluations. A total of 273 participants were retained in this final data set, meaning that 30 of the original 303 participants did not produce a single physical attribute (as determined by the two raters).

\section{Results}

Evaluations of physical attributes were positive, $M=$ $4.52, S D=1.74,95 \%$ CI [4.32, 4.73], $t(272)=4.97$, $p<.001$, suggesting that even physical attributes are more positive than negative and thus adhere to the frequency principle. As in past studies, these ratings were moderated by condition. However, as expected, only the main effect of Comparison was significant for ratings of physical attributes, $F(1,269)=12.36, p<.001$, partial $e t a^{2}=.04$, such that similarities were rated more positively $(M=4.88, S E=.15)$ compared to differences $(M=4.16, S E=.15)$. The main effect of Target, $F(1,273)=.09, p=.77$ and the Target $\mathrm{x}$ Comparison interaction, $F(1,269)=.24, p=.62$, were not statistically significant (see Figure 10).
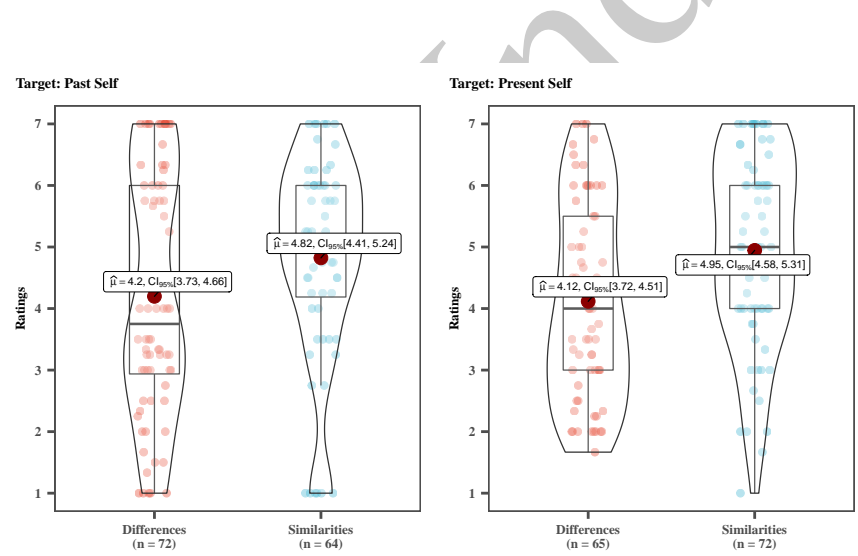

Figure 10

Study 7: Physical attributes are rated positively, but less so when thinking about differences. The evaluative asymmetry is not found when evaluating physical traits.

\section{Discussion}

As expected from an ecological perspective, Study 7 did not show an interaction between target and comparison conditions. The only significant effect that emerged when participants evaluated physical traits was the main effect of Comparison, such that differences were rated less positively than similarities. This study provides the clearest evidence against the motivated self-perception account so far, as there is little reason to assume that participants are not motivated to enhance their physical attributes (e.g., to perceive themselves in good health and physical standing). The more likely explanation is that people are reporting an accurate perception of the self over time. Because physical attributes tend to improve in early life but then stabilize (and even decline) later in life, present differences will tend to be negative as well. That is, although physical attributes of the present self are more positive than negative overall, the differences-arenegative phenomenon is not buffered by continued improvement through middle and later life. The focus on physical attributes changed a central property from he temporal evaluative information ecology, namely that positive information is prevalent, Rather, in middle and later life, physical attributes should become relatively more negative. The previous interaction of comparison mode and target thereby is most likely due to the combination of positivity prevalence with factual growth. Study 7 thereby suggests an interesting test of this assumption; as the growth is most likely negatively accelerated (i.e., older people should show less growth compared to younger people $<$ Ref? $>$ ), the observed interaction in the previous studies should vary as a function of participant age. Study 8 addresses this implication by combining the data from previous studies and examining temporal self-appraisal effects across the lifespan.

\section{Study 8: Temporal Comparison Across the Lifespan}

For older adults, we expected negative evaluations of past differences to become weaker and negative evaluations of present self differences to become stronger, because older adults do not experience improvement at the same rate as younger adults (i.e., negatively accelerated growth curve). Evidence for moderation by age, in these predicted directions, would be strong evidence that temporal self-appraisals reveal mostly accurate perceptions of self attributes over time. This pattern of results would also be a strong case against a motivational account, because a motivational account would still predict that older adults practice past self derogation, despite the fact that they have been shown to perceive little improvement, and even decline, from their past selves (Fleeson and Heckhausen, 1997; Ryff, 1991). It has been argued that older adults would choose to evaluate present attributes that would have the greatest impact on selfworth, for instance, wisdom or compassion, and derogate the past self on these dimensions in order to perceive improvement (see Wilson and Ross, 2001). If older adults are free to 
choose, but do not show the past self derogation effect in the same way as younger adults, the motivational account would fail to explain the data as well as the cognitive-ecological account.

\section{Method}

We combined the data from the studies in which participants evaluated self-attributes in a between-subjects design (Studies 1, 2, 4, 5, and 7). The combined sample included 1,214 participants $\left(M_{\text {age }}=36.91, S D_{\text {age }}=11.61\right)$. A mixedeffects regression model was used to test the hypothesis that the evaluative asymmetry found consistently in prior studies would be particularly apparent for younger adults. We included mean attribute ratings as the outcome and Target, Comparison, and Age as predictors, with all two and threeway interactions. A random intercept of ratings was specified across studies to account for between-study variation.

\section{Results}

There was a small, but significant, three-way interaction among Target, Comparison, and Age, $b=.049, S E=$ $.02, t(1209.62)=3.04, p=.002$. Including the three-way interaction increased model fit significantly over a model including only main effects, $\chi^{2}(4)=87.85, p<.001$, and a model including only main effects and two-way interactions, $\chi^{2}(1)=9.21, p=.002$ (Figure 11).

We decomposed the three-way interaction by first calculating Johnson-Neyman significance regions for the Target $x$ Comparison interaction across participant age. The interaction was only significant for participants younger than 52.78 years old ( $p<.05$ ), suggesting that the interaction (or evaluative asymmetry) found in prior studies is stronger for younger participants in the sample.

Further decomposition of this interaction revealed that the past self disparagement effect was not significant in the similarities condition and only significant $(p<.05)$ for participants younger than age 56.42 in the differences condition (Figure 11, top panel). In other words, disparagement of the past self only occurred for younger participants when evaluating differences. We also examined in which conditions, and at what age, the differences-are-negative effect was significant. When focused on the present self, differences were more negative for participants older than $32.30(p<.05)$ but when focused on the past self, differences were more negative for the entire range of ages in the combined sample (Figure 11, bottom panel).

A final interpretation of the three-way interaction was made by looking at the simple slopes of age on ratings, within the Target and Comparison conditions. present self ratings became more negative with age when focused on differences, simpleslope $=-.02, S E=.01, p<.01$, but more positive when focused on differences, simpleslope $=.03$, $S E=.01, p<.01$. past self ratings did not change significantly with age when focused on similarities, simpleslope $=$ $.01, S E=.01, p=.18$, whereas present self ratings be- came more positive with age when focused on similarities, simpleslope $=.02, S E=.01, p=.01$.

\section{Discussion}

The results from the combined data follow the predictions from the temporal evaluative information ecology model. For younger adults, past differences are overwhelmingly negative relative to all other comparisons. But as one ages, these negative evaluations become less pronounced; indeed, past differences become more positive and present differences more negative over the life span. Overall, older adults evaluate all differences as more negative. Although older adults could choose to derogate only past selves, or praise only present selves, they do not do so. Evidence of a selfperception motivated by the need for self-enhancement does not seem to exist for older adults.

\section{General Discussion}

It seems obvious that people are motivated by a desire to feel good about themselves. So, it is understandable that a theory of temporal self-appraisal would apply this core aspect of the self to explain the observed effects of temporal comparisons. However, as we have argued and now shown, effects of temporal self-appraisal may follow directly from basic cognitive and ecological aspects of comparative judgement. Can people arrive at a negative evaluation of the past self without being motivated to self-enhance? Clearly, the answer is "yes" as our findings, both simulated and experimental, can attest. Because people evaluate targets on the basis of their unique features relative to some standard, and because unique features of those targets are statistically likely to be negative in the typical evaluative ecology, the resulting evaluation is also likely to be negative (Alves et al., 2017). We show that the same principles applies beyond comparisons of targets to comparisons of the self over time.

Our research departs from prior research in one important way. We ask participants to generate relative judgements of past and present selves, whereas in past research, participants did not (although they could have been making them implicitly; Wilson and Ross, 2001). This is an important difference because testing the full motivational account requires testing two plausible routes to self-enhancement: past self disparagement and present self praise. Under the motivational framework, people should be particularly motivated to downplay the positivity of the past, and exaggerate the positivity of the present, when focused on differences. The latter is the crucial test, because the cognitive-ecological model would make the opposite prediction, as focusing on differences is statistically likely to produce more negative evaluations. None of our studies provide evidence in favor of present self praise.

Altogether, our findings more closely match what would be expected from basic comparison processes occurring in an information ecology with known properties. When positive 

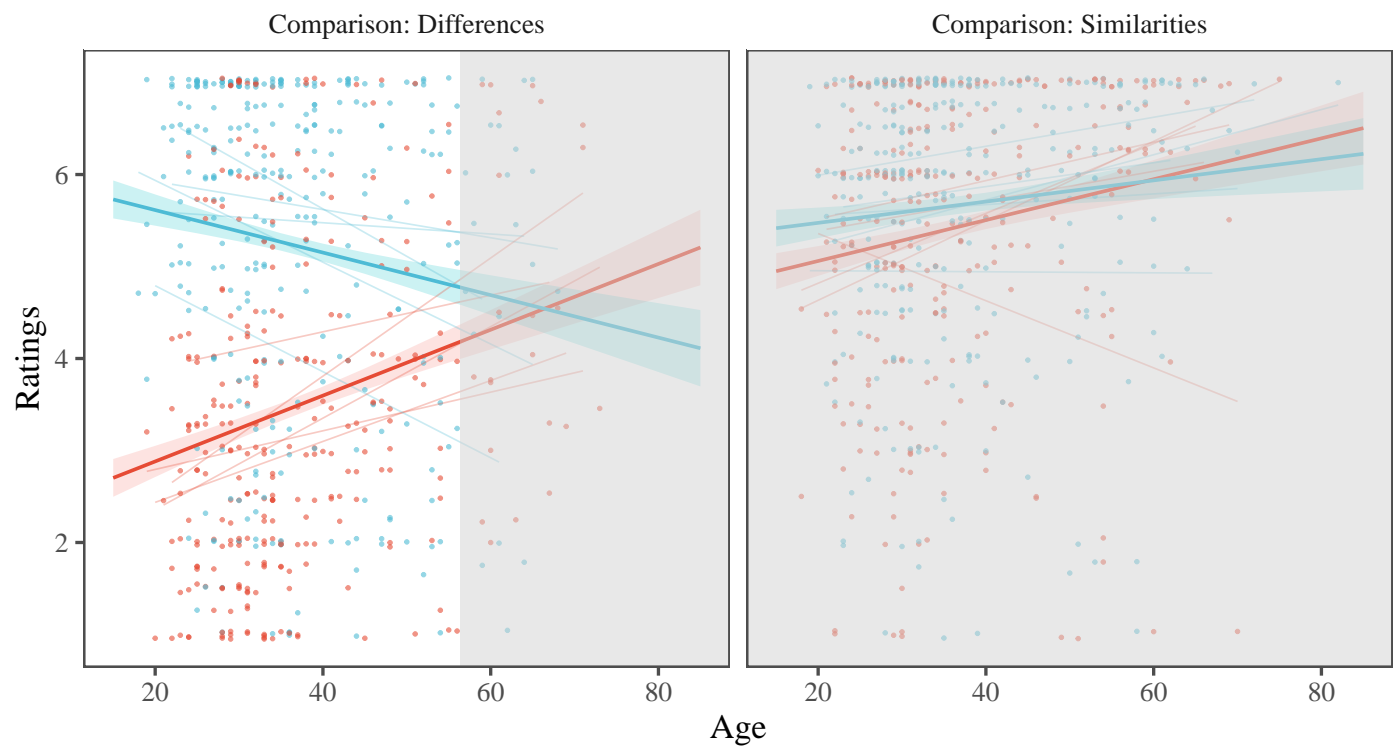

Target

- Past Self

- Present Self

Note: Non-shaded areas reflect ages where differences across Target are significant at $p<.05$
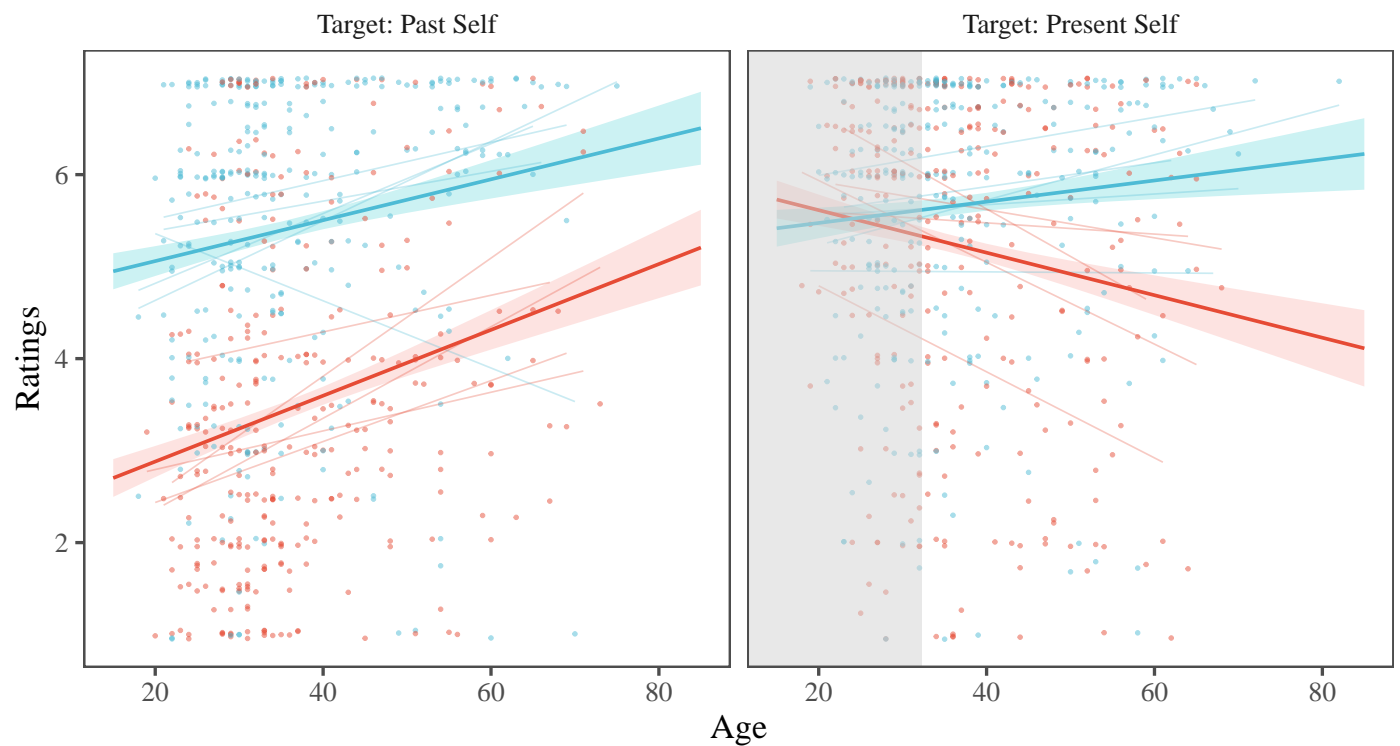

Comparison

- Differences

Age

Note: Non-shaded areas reflect ages where differences across Comparison are significant at $p<.05$

\section{Figure 11}

Study 8: past self attributes are evaluated most negatively when focused on differences, but only for younger participants. This asymmetry is largely diminished for older participants. Bold regression lines represent overall effects from an OLS linear model collapsing across study and thin lines represent effects from each study.

attributes are more frequent and more similar, the self will be more negative (or less positive) on average when evaluated on the basis of its differences. This outcome is less pronounced for the present self because of a third property of the temporal information ecology, and that is that positive information is reinforced over time which leads to actual improvement. This third principle balances negative present differences with positive ones.

\section{Changing the Ecology versus Changing Motivation}

The reason why we think that the cognitive-ecological model is a better fit to the data is because we observed predicted changes in the outcomes of temporal self-appraisal when the information ecology was changed. We did not observe such changes when we attempted to influence and measure participants' motivation. In crucial tests of the evaluative information ecology model of social comparison, re- 
versing the information ecology (e.g., to make negative information more frequent than positive information) was also shown to produce consistent changes to the consequences of social comparison. For instance, although focusing on differences in an ecology that favored positive information produced negative evaluations of new individuals from an outgroup, those same individuals were evaluated positively when the information ecology favored negative information (Alves et al., 2018). We observe changes to the consequences of temporal self-comparison in Studies 7 and 8, when participants were asked to evaluate physical characteristics and when we examined comparison effects across the life span. In Study 7, the typical asymmetry in temporal self-appraisal was replaced with a main effect, such that differences of both the past and present selves were evaluated less positively. Similarly, both past and present attributes were evaluated less positively by older adults when we combined all samples (this is akin to the main effect found in the no-change scenario in the simulation study). Indeed, there was a trend for older adults to evaluate past differences more positively than present differences-a reversal of the asymmetry found for younger adults (this is akin to the random-change scenario in the simulation study).

Why would the comparison asymmetry change in these ways? One explanation might be that motivation to selfenhance is reduced when evaluating physical characteristics, or when one is getting older. But this seems unlikely. For one, physical health is considered one of many "ulterior" interests which are "relevant to virtually all experiences that bear on the well-being of the self" (Alicke and Sedikides, 2009 , p. 7). Moreover, research has shown that the selfenhancement motive does indeed apply to physical traits and attractiveness (Alicke and Sedikides, 2009; Bleske-Rechek et al., 2008; Epley and Whitchurch, 2008; Gabriel et al., 1994). It is reasonable to predict, then, that when given the chance to select and evaluate physical characteristics that one has gained over time (i.e., present differences) participants would be motivated to enhance their physical attributes. Apparently, they do not do this (Study 7).

Secondly, it seems that older adults do self-enhance despite experiencing drastic physical, occupational, and societal change (Trzesniewski et al., 2011). For instance, older adults exhibit what is known as the subjective age biasfeeling younger than one actually is (Teuscher, 2009). Other research has shown that older adults self-enhance on physical attributes, and doing so can have a marked well-being benefit (Bailis et al., 2008). However, other research notes that self-enhancement in older adulthood is constrained by reality, and thus, people tend to self-enhance on attributes that afford some interpretive flexibility, such as ambiguous traits (vs. specific traits; Dunning et al., 1989). Taken together, these findings suggest that older adults can, and do, enhance themselves, even if it takes the form of biased selection of attributes that afford the perception of positivity. Despite this fact, older adults in our sample did not self-enhance when it may have served them most, such as when evaluating present self differences.

A more plausible explanation for the findings of Studies 7 and 8 is that the temporal information ecology has changed. It is a biological inevitability that our physical attributes decline over the course of the lifespan, and begin as early as our 20s and 30s (Hall et al., 2017; Thompson et al., 2014). Thus, as we get older actual improvement begins to slow down and the information ecology begins to favor negative and positive attributes equally; and perhaps the ecology reverses completely under some circumstances (e.g., in extreme old age or when one contracts a terminal illness), or starts to resemble the random-change scenario in our simulation study. Without the growth principle acting to reinforce and add positive attributes (and remove negative attributes) to the ecology, the evaluative asymmetry found in Studies 1-6 disappears.

\section{Implications for Self-Continuity}

Self-continuity, or the feeling that one's present self is connected with past and future selves, is often viewed as a precursor to psychological health and well-being, shown to be associated with successful long-term relationships and a supporter of life-satisfaction, to name just a few Sani, 2010. For this reason, it is argued that people need to maintain selfcontinuity (Bluck and Alea, 2008) which implies that selfcontinuity is something that people can construct themselves; a self-perception that is needed for positive psychological functioning. Our current model suggests, however, that the link between self-continuity and positive psychological outcomes could be a natural result of evaluations of the self over time in a known information ecology. When asked to consider if oneself is continuous and stable over time, some people may test the hypothesis "how have I stayed the same?" and look for similarities in the self over time. This evaluation is likely to bring to mind positive self-attributes. People may also focus on the attributes first, rather than the comparison. Making a judgement about self-continuity could start with selecting an important or defining attribute and testing whether that attribute has remained a defining characteristic over time. If most people are positive most of the time, selecting positive traits to test this hypothesis is likely to result in a heightened sense of continuity.

Thinking about self-continuity as an interaction between temporal self-comparison and the temporal evaluative information ecology might lead to novel hypotheses. For instance, it should be the case that self-continuity is associated with less positive outcomes in an evaluative ecology that favors negative information. Indeed, if things have always been bad, looking for similarities should bring to mind mostly negative information, making self-continuity a negative experience. Future research should aim to incorporate aspects of the temporal evaluative information ecology into the study 
of self-continuity to gain more insight on the source of selfcontinuity and its relation to psychological well-being. For instance, it has been shown that younger adults report lower self-continuity and self-concept clarity than older adults, but are more likely to use their autobiographies for the purpose of developing a sense of continuity (Bluck and Alea, 2008). How does chronic focus on similarities and differences shape these trends, and how would these comparisons interact with changes to the evaluative information ecology? Very little is known about these basic cognitive-ecological foundations of self-continuity.

\section{The Growth Principle}

One of the more novel hypotheses of the present research is the notion that positive information reinforces itself over time (see Table 1 and Figure 1). However, this contribution is limited by a lack of direct supporting evidence. We have strong reasons to believe that positive information is reinforced over time, but we do not know whether this is due to the diversity principle as described in the Introduction. Future research should confirm that positive attributes strengthen and grow over time because these attributes are more similar to one another. Additionally, it should be confirmed that new positive attributes that individuals gain are highly contingent on one or more existing positive attributes. New statistical methods and tools would allow us to test these predictions using attribute network models (Dalege et al., 2017; Dalege et al., 2018). In future research, measures of network strength for both positive and negative attributes could be used to predict variability in temporal self-appraisal effects.

This growth principle would also predict that, for much of one's life, the diversity of positive attributes should shrink over time. This principle could explain why self-concept clarity, or the feeling that one's self-concept is clearly and confidently defined, is so strongly associated with positive self-regard (Campbell et al., 1996) and increases with age (Bluck and Alea, 2008). Over time, positive attributes tend to group tightly into a strongly connected attribute cluster. These attributes would be more accessible in the self-concept and, because they reinforce one another, would be judged more confidently and clearly part of one's self. More research is needed to better understand what these attribute networks look like across the life span, and how they are related to temporal self-appraisal and other related aspects of the self, such as clarity and continuity.

\section{Conclusion}

We set out to explain the self-enhancement function of temporal comparison in terms of established cognitiveecological principles that follow from known properties of the information ecology. Although people are surely motivated to see themselves as better today than they were in the past, it is not necessary that people are motivated to arrive at this self-evaluation. Because positive information is more similar and frequent, and more strongly reinforced over time, we've argued and now shown that evaluations of the self based on differences to the past self will typically result in a relatively positive evaluation of the present self. This result appears to be uninfluenced by factors that would increase or decrease the motivation to self-enhance, but is influenced by factors that change the properties of the information ecology. Because we test the full range of possible self-comparisons, and factor in known properties of the information ecology, this research offers a novel and important extension to temporal self-appraisal theory, and provides a more parsimonious account of how people arrive at self-evaluations that favor the present self, even if no actual improvement has occurred over time.

\section{References}

Albert, S. (1977). Temporal comparison theory. American Psychologist, 84(9), 485-503. https://doi.org/10. 1037/h0021465

Alicke, M. D., \& Sedikides, C. (2009). Self-enhancement and self-protection: What they are and what they do. European Review of Social Psychology, 20(1), 1-48. https://doi.org/10.1080/10463280802613866

Alves, H. (2018). Sharing rare attitudes attracts. Personality and Social Psychology Bulletin, 44(8), 1270-1283. https://doi.org/10.1177/0146167218766861

Alves, H., Högden, F., Gast, A., Aust, F., \& Unkelbach, C. (2020). Attitudes from mere co-occurrences are guided by differentiation. Journal of Personality and Social Psychology, 119(3), 560-581. https:// doi.org/10.1037/pspa0000193

Alves, H., Koch, A., \& Unkelbach, C. (2017a). The 'common good' phenomenon: Why similarities are positive and differences are negative. Journal of Experimental Psychology: General, 146(4), 512-528. https : //doi.org/10.1037/xge0000276

Alves, H., Koch, A., \& Unkelbach, C. (2017b). Why good is more alike than bad: Processing implications [Publisher: Elsevier Ltd]. Trends in Cognitive Sciences, 21(2), 69-79. https://doi.org/10.1016/j.tics.2016. 12.006

Alves, H., Koch, A., \& Unkelbach, C. (2018). A cognitiveecological explanation of intergroup biases [Publisher: SAGE PublicationsSage CA: Los Angeles, CA]. Psychological Science, 29(7), 1126-1133. https://doi.org/10.1177/0956797618756862

Alves, H., Koch, A., \& Unkelbach, C. (2019). The differential similarity of positive and negative information-an affect-induced processing outcome? Cognition and Emotion, 33(6), 1224-1238. https://doi . org/10.1080/02699931.2018.1549022 
Bailis, D. S., Chipperfield, J. G., Perry, R. P., Newall, N. E., \& Haynes, T. L. (2008). Exploring the commonalities between adaptive resources and selfenhancement in older adults' comparative judgments of physical activity [Publisher: SAGE Publications Inc]. Journal of Aging and Health, 20(8), 899-919. https : / / doi . org / 10 . 1177/ 0898264308324636

Baldwin, M., Biernat, M., \& Landau, M. J. (2015). Remembering the real me: Nostalgia offers a window to the intrinsic self. Journal of Personality and Social Psychology, 108(1), 128-147. https://doi.org/10.1037/ a0038033

Baumeister, R. F. (1999). Self-concept, self-esteem, and identity., In Personality: Contemporary theory and research, 2nd ed. Chicago, IL, US, Nelson-Hall Publishers.

Biernat, M. (2003). Toward a broader view of social stereotyping. American Psychologist, 58(12), 1019-1027. https://doi.org/10.1037/0003-066X.58.12.1019

Bleske-Rechek, A., Remiker, M. W., \& Baker, J. P. (2008). Narcissistic men and women think they are so hotbut they are not. Personality and Individual Differences, 45(5), 420-424. https://doi.org/10.1016/j. paid.2008.05.018

Bluck, S., \& Alea, N. (2008). Remembering being me: The self continuity function of autobiographical memory in younger and older adults, In Self continuity: Individual and collective perspectives. New York, NY, US, Psychology Press.

Bluck, S., Alea, N., Habermas, T., \& Rubin, D. C. (2005). A tale of three functions: The self-reported uses of autobiographical memory [Publisher: Guilford Press]. Social Cognition, 23(1), 91-117. https://doi.org/10. 1521/soco.23.1.91.59198

Bluck, S., \& Levine, L. J. (1998). Reminiscence as autobiographical memory: A catalyst for reminiscence theory development [Publisher: Cambridge University Press]. Ageing $\mathcal{F}$ Society, 18(2), 185-208.

Burnham, M. J., Le, Y. K., \& Piedmont, R. L. (2018). Who is mturk? personal characteristics and sample consistency of these online workers. Mental Health, Religion $\mathcal{F}$ Culture, 21(9-10), 934-944. https://doi.org/ 10.1080/13674676.2018.1486394

Campbell, J. D., Trapnell, P. D., Heine, S. J., Katz, I. M., Lavallee, L. F., \& Lehman, D. R. (1996). Selfconcept clarity: Measurement, personality correlates, and cultural boundaries. Journal of Personality and Social Psychology. https://doi.org/10.1037/ 0022-3514.70.1.141

Cialdini, R. B., Borden, R. J., Thorne, A., Walker, M. R., Freeman, S., \& Sloan, L. R. (1976). Basking in reflected glory: Three (football) field studies. [Pub- lisher: American Psychological Association]. Journal of personality and social psychology, 34(3), 366.

Corcoran, K., Crusius, J., \& Mussweiler, T. (2011). Social comparison: Motives, standards, and mechanisms (D. Chadee, Ed.). In D. Chadee (Ed.), Theories in social psychology. Wiley-Blackwell.

Dai, H., \& Li, C. (2019). How experiencing and anticipating temporal landmarks influence motivation [Publisher: Elsevier]. Current Opinion in Psychology, 26, 44-48. https://doi .org/10.1016/J.COPSYC. 2018.04.012

Dalege, J., Borsboom, D., Van Harreveld, F., Waldorp, L. J., \& Van Der Maas, H. L. (2017). Network structure explains the impact of attitudes on voting decisions [Publisher: Nature Publishing Group _eprint: 1704.00910]. Scientific Reports, 7(1). https://doi. org/10.1038/s41598-017-05048-y

Dalege, J., Borsboom, D., van Harreveld, F., \& van der Maas, H. L. (2018). The attitudinal entropy (AE) framework as a general theory of individual attitudes [Publisher: Routledge]. Psychological Inquiry, 29(4), 175-193. https :// doi .org/10.1080/ 1047840X.2018.1537246

Dalege, J., Borsboom, D., van Harreveld, F., \& van der Maas, H. L. (2019). A network perspective on attitude strength: Testing the connectivity hypothesis. Social Psychological and Personality Science, 10(6), 746756. https://doi.org/10.1177/1948550618781062

Demo, D. H. (1992). The self-concept over time: Research issues and directions. Annual Review of sociology, 18(1), 303-326.

Ditto, P. H., \& Boardman, A. F. (1995). Perceived accuracy of favorable and unfavorable psychological feedback. Basic and Applied Social Psychology, 16(1), 137-157. https://doi.org/10.1080/01973533.1995. 9646106

Doosje, B., Spears, R., \& Koomen, W. (1995). When bad isn't all bad: Strategic use of sample information in generalization and stereotyping. Journal of Personality and Social Psychology, 69(4), 642-655. https: //doi.org/10.1037/0022-3514.69.4.642

Dumas, F., Fagot, J., Davranche, K., \& Claidière, N. (2017). Other better versus self better in baboons: An evolutionary approach of social comparison [Publisher: Royal Society]. Proceedings of the Royal Society B: Biological Sciences, 284(1855), 20170248. https:// doi.org/10.1098/rspb.2017.0248

Dunning, D., Meyerowitz, J. A., \& Holzberg, A. D. (1989). Ambiguity and self-evaluation: The role of idiosyncratic trait definitions in self-serving assessments of ability [Place: US Publisher: American Psychological Association]. Journal of Personality and Social 
Psychology, 57(6), 1082-1090. https://doi.org/10. 1037/0022-3514.57.6.1082

Epley, N., \& Whitchurch, E. (2008). Mirror, mirror on the wall: Enhancement in self-recognition. Personality and Social Psychology Bulletin, 34(9), 1159-1170. https://doi.org/10.1177/0146167208318601

Epstude, K., \& Mussweiler, T. (2009). What you feel is how you compare: How comparisons influence the social induction of affect. Emotion, 9(1), 1-14. https: //doi.org/10.1037/a0014148

Festinger, L. (1954). A theory of social comparison processes. Human Relations, 7(2), 117-140. https :// doi.org/10.1177/001872675400700202

Fiedler, K. (2000). Beware of samples! a cognitiveecological sampling approach to judgment biases [Place: US Publisher: American Psychological Association]. Psychological Review, 107(4), 659-676. https://doi.org/10.1037/0033-295X.107.4.659

Fleeson, W., \& Heckhausen, J. (1997). More or less" me" in past, present, and future: Perceived lifetime personality during adulthood. [Publisher: American Psychological Association]. Psychology and Aging, 12(1), 125.

Gabriel, M. T., Critelli, J. W., \& Ee, J. S. (1994). Narcissistic illusions in self-evaluations of intelligence and attractiveness. Journal of Personality, 62(1), 143 155. https://doi.org/10.1111/j.1467-6494.1994. tb00798.x

Gershoff, A. D., Mukherjee, A., \& Mukhopadhyay, A. (2007). Few ways to love, but many ways to hate: Attribute ambiguity and the positivity effect in agent evaluation [Publisher: Oxford Academic]. Journal of Consumer Research, 33(4), 499-505. https://doi. org/10.1086/510223

Habermas, T., \& Bluck, S. (2000). Getting a life: The emergence of the life story in adolescence [Publisher: American Psychological Association]. Psychological Bulletin, 126(5), 748-769. https://doi.org/10. 1037/0033-2909.126.5.748

Haddock, G. (2004). Temporal self-appraisal and attributional focus [ISBN: 0022-1031]. Journal of Experimental Social Psychology, 40(6), 787-794. https: //doi.org/10.1016/j.jesp.2004.04.004

Hall, K. S., Cohen, H. J., Pieper, C. F., Fillenbaum, G. G., Kraus, W. E., Huffman, K. M., Cornish, M. A., Shiloh, A., Flynn, C., Sloane, R., Newby, L. K., \& Morey, M. C. (2017). Physical performance across the adult life span: Correlates with age and physical activity [Publisher: Oxford Academic]. The Journals of Gerontology: Series A, 72(4), 572-578. https://doi.org/10.1093/gerona/glw120

Heidegger, M. (1962). Being and time. New York.
Herr, P. M. (1986). Consequences of priming: Judgment and behavior [ISBN: 1939-1315(Electronic),00223514(Print) Place: US Publisher: American Psychological Association]. Journal of Personality and Social Psychology, 51(6), 1106-1115. https://doi.org/ 10.1037/0022-3514.51.6.1106

Higgins, E. T., \& Lurie, L. (1983). Context, categorization, and recall: The "change-of-standard" effect [ISBN: 0010-0285]. Cognitive Psychology, 15(4), 525-547. https :// doi . org/https :// doi . org/10 . 1016/00100285(83)90018-X

Kahneman, D., \& Miller, D. T. (1986). Norm theory. comparing reality to its alternatives. Psychological Review, 93(2), 136-153. https://doi . org/10 .1037/0033 295X.93.2.136

Keupp, S., Titchener, R., Bugnyar, T., Mussweiler, T., \& Fischer, J. (2019). Competition is crucial for social comparison processes in long-tailed macaques [Publisher: Royal Society]. Biology Letters, 15(3), 20180784. https://doi.org/10.1098/rsbl.2018.0784

Krueger, J., \& Clement, R. W. (1994). Memory-based judgments about multiple categories: A revision and extension of tajfel's accentuation theory. [Publisher: American Psychological Association]. Journal of Personality and Social Psychology, 67(1), 35.

Krueger, J., Rothbart, M., \& Sriram, N. (1989). Category learning and change: Differences in sensitivity to information that enhances or reduces intercategory distinctions. [Publisher: American Psychological Association]. Journal of Personality and Social Psychology, 56(6), 866.

Langer, E. J. (1975). The illusion of control. Journal of Personality and Social Psychology, 32(2), 311-328. https://doi.org/10.1037/0022-3514.32.2.311

Leary, M. R. (1999). Making sense of self-esteem. Current Directions in Psychological Science, 8(1), 32-35. https://doi.org/10.1111/1467-8721.00008

Leising, D., Ostrovski, O., \& Zimmermann, J. (2013). are we talking about the same person here?": Interrater agreement in judgments of personality varies dramatically with how much the perceivers like the targets [Publisher: SAGE Publications Inc]. Social Psychological and Personality Science, 4(4), 468474. https://doi.org/10.1177/1948550612462414

Markus, H., \& Nurius, P. (1987). Possible selves: The interface between motivation and the self-concept, In Self and identity: Psychosocial perspectives. Oxford, England, John Wiley \& Sons.

McAdams, D. P. (2008). Dan p. McAdams, 2008 (John, Robins, \& Pervin, Eds.; 3rd ed.) [Section: 8]. In John, Robins, \& Pervin (Eds.), Handbook of personality: Theory and research2 (3rd ed.). Section: 8. New York, NY, Guilford Press. 
McAdams, D. P., \& McLean, K. C. (2013). Narrative identity. Current Directions in Psychological Science. https://doi.org/10.1177/0963721413475622

McAdams, D. P., \& Pals, J. L. (2006). A new big five: Fundamental principles for an integrative science of personality [ISBN: 1935-990X Publisher: US: American Psychological Association]. American psychologist, 61(3), 204-217.

Medin, D. L., Goldstone, R. L., \& Gentner, D. (1993). Respects for similarity. Psychological Review, 100(2), 254-278. https://doi.org/10.1037/0033-295X.100. 2.254

Mezulis, A. H., Abramson, L. Y., Hyde, J. S., \& Hankin, B. L. (2004). Is there a universal positivity bias in attributions? a meta-analytic review of individual, developmental, and cultural differences in the selfserving attributional bias. Psychological Bulletin, 130(5), 711-747. https://doi.org/10.1037/00332909.130.5.711

Mussweiler, T. (2003). Comparison processes in social judgment: Mechanisms and consequences [ISBN: 19391471(Electronic),0033-295X(Print) Place: US Publisher: American Psychological Association]. Psychological Review, 110(3), 472-489. https :// doi . org/10.1037/0033-295X.110.3.472

O'brien, E., \& Kardas, M. (2016). The implicit meaning of (my) change. https://doi.org/10.1037/pspi0000073

Peetz, J., \& Wilson, A. E. (2013). The post-birthday world: Consequences of temporal landmarks for temporal self-appraisal and motivation. [ISBN: 19391315(Electronic),0022-3514(Print) Place: US Publisher: American Psychological Association]. Journal of Personality and Social Psychology, 104(2), 249-266. https://doi.org/10.1037/a0030477

Peetz, J., \& Wilson, A. E. (2014). Marking time: Selective use of temporal landmarks as barriers between current and future selves. Personality and Social Psychology Bulletin, 40(1), 44-56. https://doi.org/10. $1177 / 0146167213501559$

Pronin, E., \& Ross, L. (2006). Temporal differences in trait self-ascription: When the self is seen as an other [Publisher: US: American Psychological Association]. Journal of Personality and Social Psychology, 90(2), 197-209. https : // doi . org/10 . 1037/0022 3514.90.2.197

Ricoeur, P. (1991). Narrative identity. Philosophy today, 35(1), 73-81.

Robins, R. W., \& Trzesniewski, K. H. (2005). Self-Esteem Development Across the Lifespan. Current Directions in Psychological Science, 14(3), 158-162. https://doi.org/10.1111/j.0963-7214.2005.00353.x
Ross, M., \& Wilson, A. E. (2000). Constructing and apprasing past selves, In Memory, brain, and belief. Cambridge, MA, US, Harvard University Press.

Ross, M., \& Wilson, A. E. (2003). Autobiographical memory and conceptions of self [Publisher: SAGE PublicationsSage CA: Los Angeles, CA]. Current Directions in Psychological Science, 12(2), 66-69. https: //doi.org/10.1111/1467-8721.01228

Ryff, C. D. (1991). Possible selves in adulthood and old age: A tale of shifting horizons. [Publisher: American Psychological Association]. Psychology and aging, 6(2), 286.

Sani, F. (2010, August 18). Self continuity: Individual and collective perspectives [Google-Books-ID: wPFGBQAAQBAJ]. Psychology Press.

Schmitt, V., Federspiel, I., Eckert, J., Keupp, S., Tschernek, L., Faraut, L., Schuster, R., Michels, C., SennhennReulen, H., Bugnyar, T., Mussweiler, T., \& Fischer, J. (2016). Do monkeys compare themselves to others? Animal Cognition, 19(2), 417-428. https://doi. org/10.1007/s10071-015-0943-4

Sedikides, C., Gaertner, L., \& Toguchi, Y. (2003). Pancultural self-enhancement. Journal of Personality and Social Psychology, 84(1), 60-79. https://doi.org/10. 1037/0022-3514.84.1.60

Sedikides, C., Wildschut, T., Cheung, W. Y., Hepper, E. G., Vail, K., Brackstone, K., Routledge, C., Arndt, J., Zhou, X., \& Vingerhoets, A. J. (2016). Nostalgia fosters self-continuity: Uncovering the mechanism (social connectedness) and consequence (eudaimonic well-being). Emotion. https://doi.org/10. 1037/emo0000136

Sherif, M., \& Hovland, C. I. (1961). Social judgment: Assimilation and contrast effects in communication and attitude change [Publication Title: Social judgment: Assimilation and contrast effects in communication and attitude change.]. Oxford, England, Yale Univer. Press.

Simonsohn, U. (2015). [17] No-way Interactions. The Winnower. https://doi .org/10.15200/winn. 142559. 90552

Suddendorf, T., \& Busby, J. (2003). Mental time travel in animals? Trends in Cognitive Sciences, 7(9), 391-396. https://doi.org/10.1016/S1364-6613(03)00187-6

Suls, J. M., \& Miller, R. L. (1977). Social comparison processes: Theoretical and empirical perspectives. Hemisphere.

Suls, J., Collins, R. L., \& Wheeler, L. (2019, December 20). Social comparison, judgment, and behavior [Google-Books-ID: 6FO_DwAAQBAJ]. Oxford University Press.

Tesser, A. (1988). Toward a self-evaluation maintenance model of social behavior (L. Berkowitz, Ed.). In L. 
Berkowitz (Ed.), Advances in experimental social psychology. Academic Press. https://doi.org/10. 1016/S0065-2601(08)60227-0

Teuscher, U. (2009). Subjective age bias: A motivational and information processing approach [Publisher: SAGE Publications Ltd]. International Journal of Behavioral Development, 33(1), 22-31. https://doi.org/ $10.1177 / 0165025408099487$

Thompson, J. J., Blair, M. R., \& Henrey, A. J. (2014). Over the hill at 24: Persistent age-related cognitive-motor decline in reaction times in an ecologically valid video game task begins in early adulthood [Publisher: Public Library of Science]. PLOS ONE, 9(4), e94215. https:// doi . org/10.1371/journal . pone. 0094215

Trzesniewski, K. H., Kinal, M., \& Donnellan, M. B. (2011). Self-enhancement and selfprotection in a developmental context [Publisher: Guilford Press New York, NYS]. Handbook of self-enhancement and self-protection, 341-357.

Tversky, A., \& Gati, I. (1978). Studies of similarity. Cognition and categorization. Hillsdale, Erlbaum.

Unkelbach, C., Alves, H., \& Koch, A. (2020). Negativity bias, positivity bias, and valence asymmetries: Explaining the differential processing of positive and negative information, In Advances in experimental social psychology. Elsevier. https:// doi . org/10 . 1016/bs.aesp.2020.04.005
Unkelbach, C., Koch, A., \& Alves, H. (2019). The evaluative information ecology: On the frequency and diversity of "good" and "bad". European Review of Social Psychology, 30(1), 216-270. https://doi.org/10. 1080/10463283.2019.1688474

Wilson, A. E., \& Ross, M. (2000). The frequency of temporal-self and social comparisons in people's personal appraisals [ISBN: 0022-3514]. Journal of Personality and Social Psychology, 78(5), 928-942. https://doi.org/10.1037/0022-3514.78.5.928

Wilson, A. E., \& Ross, M. (2001). From chump to champ: People's appraisals of their earlier and present selves. Journal of Personality and Social Psychology, 80(4), 572-584. https://doi.org/10.1037/00223514.80.4.572

Wilson, A. E., \& Ross, M. (2003). The identity function of autobiographical memory: Time is on our side [Publisher: Taylor \& Francis Group]. Memory, 11(2), 137-149. https://doi.org/10.1080/741938210

Wood, D., \& Furr, R. M. (2016). The correlates of similarity estimates are often misleadingly positive: The nature and scope of the problem, and some solutions [Publisher: SAGE Publications Inc]. Personality and Social Psychology Review, 20(2), 79-99. https://doi.org/10.1177/1088868315581119 